\title{
Analysis of the numerical and geometrical parameters influencing the simulation of mode I and mode II delamination growth in unidirectional and textile composites
}

\author{
S. Jacques ${ }^{1 *}$, I. De Baere ${ }^{1}$ and W. Van Paepegem ${ }^{1}$ \\ ${ }^{1}$ Ghent University, Dept. of Materials Science and Engineering, Technologiepark-Zwijnaarde
} 903, 9052 Zwijnaarde, Belgium

*corresponding author: Stefan.Jacques@UGent.be; T +3293310435

\begin{abstract}
The reliability of composite structures depends, among other damage mechanisms, on their ability to withstand delaminations. In order to have a better understanding of the cohesive zone method technique for delamination simulations, a complete analysis of the multiple parameters influencing the results is necessary. In this paper the work is concentrated on the cohesive zone method using cohesive elements. First a summary of the theory of the cohesive zone method is given. A numerical investigation on the multiple parameters influencing the numerical simulation of the mode I and mode II delamination tests has been performed. The parameters such as the stabilization method, the output frequency, the friction and the computational efficiency have been taken into account. The results will be compared to an analytical solution obtained by linear elastic fracture mechanics. Additionally the numerical simulation results will be compared to the experimental results of a glass-fibre reinforced composite material for the mode I Double Cantilever Beam (DCB) and to a carbon fibre 5harness satin weave reinforced polyphenylene sulphide composite for the mode I DCB and mode II End Notched Flexure (ENF).
\end{abstract}

Keywords: Composites; critical strain energy release rate; double cantilever beam (DCB);

End notched flexure (ENF); failure mode; delamination

\section{Introduction}

Delamination is one of the most difficult and common types of damage in laminated composite structures due to the relatively weak interlaminar strengths. Delamination starts generally at geometrical discontinuities, such as laminate free edges and cut-outs. This is so because the state of stress close to a free edge in a laminate is three-dimensional, with nonzero interlaminar stresses, which grow without bound due to a singularity in the stress field at the intersection of the free-edge and the interface. Delaminations may arise in a composite under various circumstances, e.g. when subject to transverse concentrated loads, such as low/high velocity impacts arising from a falling mass, and propagate due to the loads of the structure such as dynamic loading. Finally the behaviour of the entire structure changes and in most cases a failure is unavoidable.

Since decades, methods based on fracture mechanics have been used to model delamination problems. These methods rely on the assumption of an initial existing crack or void and 
cannot be applied directly without it. In many papers stress based methods are used in order to predict the delamination initiation and this precedes the propagation calculations using the fracture mechanics. The parameters such as stress intensity factors or energy release rates require information of several elements around the crack front. Some examples of fracture mechanics based methods which were implemented in commercial finite element codes are:

- Virtual Crack Closure Technique (VCCT): Rybicki and Kanninen (1977) [1], Krueger (2004) [2].

- J-Integral: Rice (1968) [3]

Later, models using the cohesive zone method (CZM) became more and more popular for the simulation of fracture processes. The initial LEFM approaches from Inglis [4] to Westergaard [5] and Griffith [6] lead to infinite stresses at the crack tip of a perfectly sharp crack. This, of course, is non-physical since it would mean that the materials would have zero strength. Barenblatt (1959) [7] and Dugdale (1960) [8] developed a concept avoiding this infinity at the crack tip.

The cohesive zone method can be summarized as follows $[9,10]$ : all the inelastic effects that occur at the vicinity of a crack can be concentrated into a surface namely the cohesive damage zone. Based on the concept of continuum modelling, the interfacial damage mechanics takes into account the irreversible damage consistent with the laws of thermodynamics. The advantage over the continuum modelling is the ability of the technique to allow two or more material points to coexist in the same location of the undeformed body. A difference between the two techniques is the formulation: the continuum model formulates the work conjugacy based on the stresses and strains, whereas tractions $\tau_{\mathrm{j}}$ and displacement jumps $\delta$ are used to calculate the work conjugacy in the interfacial damage mechanics. Damage initiation is related to the interfacial strength $\tau_{0}$. When the area under the traction - displacement jump relation is equal to the fracture toughness $G_{c}$, the traction is reduced to zero and new crack surfaces are created. The new crack surfaces are completely formed when the displacement jump is equal to or greater than the final displacement jump $\delta_{\mathrm{f}}$. In other words, the energy dissipated at the crack propagation must be equal to the fracture toughness and following relation must be fulfilled:

$$
\int_{0}^{\delta_{j}^{f}} \tau_{j} d \delta_{j}=G_{c}
$$

Through the years several traction-separation softening laws have been developed as those given by Barenblatt and Dugdale for example [11]; Needleman developed a phenomenological model to predict the normal separation using a polynomial fit (1987) [12], Tvergaard and Hutchinson (1992) [13] proposed a trapezoidal traction; Xu and Needleman (1993) [14] and (1994) [15] used the models of Needleman to study the void nucleation at the interface between the particle and matrix, and the dynamic fracture growth at the bi-material interfaces predicting shear and normal separation; Camacho and Ortiz (1996) [16] used a linear cohesive zone method with tensile and shear cohesive relation to simulate multiple cracks under impact damage in brittle materials predicting failure by shear and normal separation in tension and shear in compression; Geubelle and Baylor (1998) [17] used a bilinear traction-separation law to simulate the crack initiation and propagation of transverse matrix cracks and delamination fronts in thin composite plates under low-velocity impact.

In this work the attention is given to the bilinear softening equation (Fig 1). 


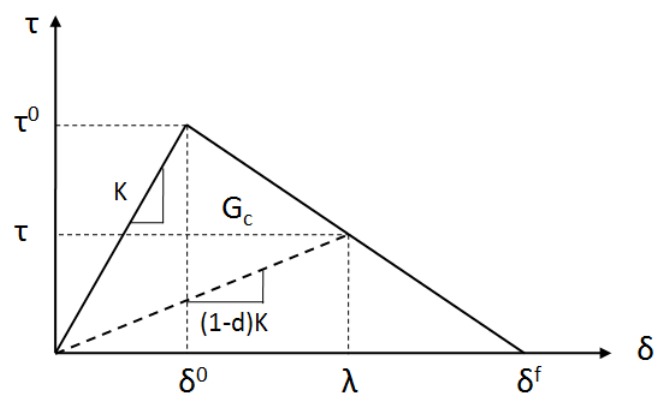

Fig 1 Bilinear cohesive traction separation law [10]

The cohesive zone model with the boundary value problem, the kinematics and constitutive relations for the formulation of the model for the delamination initiation and propagation are nicely presented by Turon and Camanho (2006) in [10]. In this manuscript the cohesive zone method, more specifically with the cohesive elements, was used for the numerical modelling of a mode I double cantilever beam (DCB) test and the mode II end notched flexure (ENF) test. The mathematical implementation can be found in [18].

\section{Goal}

A lot of research on the numerical simulation of delaminations has been performed the last decade in which multiple parameters have been studied in order to verify their impact on the results. For example Turon et al. [10] developed a material model for the cohesive element and studied the impact of the stiffness $\mathrm{K}$ and the strength $\tau_{0}$ (Fig 1) and developed an approach for the selection of the adequate mesh length of the cohesive elements in the numerical models. In [19], Alfano et al. declared that the impact of the interfacial strength is negligible unless the chosen strength is too low leading to inaccurate results. However in this work will be proven through a numerical investigation on a mode I double cantilever beam (DCB) and a mode II end notched flexure (ENF) test that not only the strength has an impact, but moreover it is the combination of the different parameters like stiffness, strength, numerical stabilization, output frequency, mesh size, and in the case of mode II the friction (external and internal), position of the sample and other parameters which will steer the results.

\section{Experimental / analytical / numerical references}

In order to validate the numerical results the numerically obtained load-displacement curves will be benchmarked to the analytical solutions. Additionally experimental results will be used for the validation of the numerical results. In the last decades a lot of research has been made in order to create standardization of methods for the material characterization and a survey can be found in [20] (1998) and in [21] followed by a more recent version (2008) [22]. In the contrary to the Mode I DCB standardization, no consensus was found after round Robin for obtaining a Mode II standard for ENF yet. One of the reasons is the unstable crack growth for some materials, the crack initiation point, the influence of friction effects on the results and the appearance of hackles for example. Alternatives were introduced like for example the 4ENF (4 point bending) test by Martin and Davidson [23], which also faced some difficulties. The influence of friction on the 3ENF and the 4ENF was described by Davidson et al. (2005) [24]. However extensive work has been done by the research community, not all necessary parameters are implemented in the manuscripts when dealing with mode I and mode II simulations, even when experimental analyses have proven that the parameters have an important impact on the final results (for example friction). 


\subsection{Mode I - DCB}

Concerning the mode I DCB simulations, a parametric analysis was performed on the material used by Turon et al. in [10]. This allowed having a good reference when obtaining numerical results of the mode I DCB tests. The material properties (elastic and damage properties) of the simulated test specimen, which is a unidirectional carbon-fibre reinforced epoxy composite, are shown in Table 1.

\begin{tabular}{|c|c|c|c|c|c|}
\hline \multicolumn{7}{|c|}{ Elastic properties } \\
\hline $\mathrm{E}_{11},[\mathrm{GPa}]$ & $\left.\mathrm{E}_{22}=\mathrm{E}_{33,}, G P a\right]$ & $\mathrm{G}_{12}=\mathrm{G}_{13,}[\mathrm{GPa}]$ & $\left.\mathrm{G}_{23}, G P a\right]$ & $v_{12}=v_{13}$ & $v_{23}$ \\
\hline 120.0 & 10.5 & 5.25 & 3.48 & 0.3 & 0.5 \\
\hline \multicolumn{5}{|c|}{ Damage related parameters } & \\
\hline$\tau_{3}^{0},[\mathrm{MPa}]$ & $\mathrm{G}_{\mathrm{IC},[\mathrm{N} / \mathrm{mm}]} \mathrm{K},\left[\mathrm{N} / \mathrm{mm}^{3}\right]$ & & \\
\hline 15 & 0.26 & $1 \mathrm{e} 6$ & & & \\
\hline
\end{tabular}

Table 1 Material properties of the carbon fibre reinforced epoxy [10]

$$
\text { where } \begin{array}{ll}
\mathrm{E}_{11} & =\text { Longitudinal Young's modulus, }[\mathrm{GPa}] \\
\mathrm{E}_{22} ; \mathrm{E}_{33} & =\text { Young's modulus in transverse directions, }[\mathrm{GPa}] \\
\mathrm{G}_{\mathrm{ij} \mathrm{i}=1,2,3 \text { and } \mathrm{j}=1,2,3} & =\text { Shear moduli in different directions, }[\mathrm{GPa}] \\
v_{\mathrm{ij} \mathrm{i}=1,2,3 \text { and } \mathrm{j}=1,2,3} & =\text { Poisson coefficients } \\
\tau_{3}^{0} & =\text { strength at failure initiation in normal direction, }[\mathrm{MPa}] \\
\mathrm{G}_{\mathrm{Ic}} & =\text { mode I critical strain energy release rate, }[\mathrm{N} / \mathrm{mm}] \\
\mathrm{K} & =\text { Penalty stiffness, }\left[\mathrm{N} / \mathrm{mm}^{3}\right]
\end{array}
$$

Once all the influencing parameters of the numerical simulations were analysed, the gained knowledge was applied on a unidirectional glass/fibre reinforced epoxy material. The mode I DCB tests of this material are explained below. Additionally the results of a mode I DCB test on CETEX material (CF/PPS 5-harness satin weave composite) will be shown.

\section{Mode I DCB tests}

The objective of a DCB test is to determine the $\mathrm{G}_{\mathrm{Ic}}$ for an interlaminar interface and the commonly used standard is the ASTM-D5528 standard [25].

\subsubsection{Test setup}

All tests have been performed on an electromechanical Instron 5800R tensile machine A calibrated load cell of $1 \mathrm{kN}$ has been used and the forces and displacements were recorded using the Blue Hill software throughout the experiment. The tests were displacement driven with accurate control of speed $(1 \mathrm{~mm} / \mathrm{min})$ and position. All the results were post-processed in Excel. The behaviour of the material under the mode I loading condition was captured visually by using a microscope at a frame rate of 30 FPS.

\subsubsection{Material and Results}

\section{GF/Epoxy}

GF/Epoxy plates were produced with the resin transfer moulding (RTM) technique. Eight layers of non-crimp GF UD fabric are packed in a mould cavity which has the shape of the desired part and the mould is closed. The polymer resin is then pumped into the cavity where an under-pressure is built up with a vacuum pump. In the last phase, the curing cycle, the mould is heated and the resin is polymerized to finally become a fibre reinforced composite. In order to obtain mode I test specimens, a kapton film $(13 \mu \mathrm{m}$ thick) is placed in the centre of the stacking of the reinforcing fibre layers. This non-adhesive film will form the initiation of 
delamination of the composite. The mechanical properties for the UD GF/Epoxy composite can be found in Table 2. The plates were sawed using a diamond saw in the dimensions corresponding to the requirements given in the ASTM standard D5528 [25].

\begin{tabular}{|c|c|c|c|c|c|c|c|c|}
\hline \multicolumn{10}{|c|}{ Elastic properties } \\
\hline $\mathrm{E}_{11}$, & $\mathrm{E}_{22}$, & $\mathrm{E}_{33}$, & $v_{12}$, & $v_{13,}$ & $v_{23}$, & $\mathrm{G}_{12}$, & $\mathrm{G}_{13}$, & $\mathrm{G}_{23}$, \\
{$[G P a]$} & {$[G P a]$} & {$[G P a]$} & {$[-]$} & {$[-]$} & {$[-]$} & {$[M P a]$} & {$[M P a]$} & {$[M P a]$} \\
\hline 38.90 & 13.30 & - & 0.25 & - & - & 5130.0 & - & - \\
\hline
\end{tabular}

Table 2 Elastic properties of the UD GF/Epoxy material

In an initial phase, 3 specimens (GFE1, GFE2 and GFE3 in Table 3) with the dimensions conform to those given in the ASTM standard D5528 were tested in order to evaluate the ASTM standard method for the fracture toughness calculations with one polished side of the specimens. Since large deflections were observed for the DCB tests for samples GFE1to GFE3 an additional test sample (GFE5 in Table 3) with $\mathrm{L}=105 \mathrm{~mm}$ was tested.

\begin{tabular}{|l|c|c|c|c|}
\hline & GFE1 & GFE2 & GFE3 & GFE5 \\
\hline Thickness t, $[\mathrm{mm}]$ & 3.00 & 3.00 & 3.00 & 3.00 \\
\hline Width $\mathrm{b},[\mathrm{mm}]$ & 23.15 & 23.15 & 23.25 & 21.30 \\
\hline Length $\mathrm{L},[\mathrm{mm}]$ & 123.40 & 123.35 & 123.60 & 105.00 \\
\hline $\mathrm{a}_{0},[\mathrm{~mm}]$ & 47.95 & 47.95 & 47.95 & 29.45 \\
\hline $\mathrm{a}_{0}$ (after precrack), $[\mathrm{mm}]$ & 56.95 & 56.95 & 57.45 & 35.45 \\
\hline
\end{tabular}

Table 3 Dimensions of the GF/Epoxy (GFE1 - GFE5) test specimens

The experimental load-displacement curves for the GF/Epoxy composite samples can be found in Fig 2. GFE5 will be used as experimental benchmark for the numerical simulations.

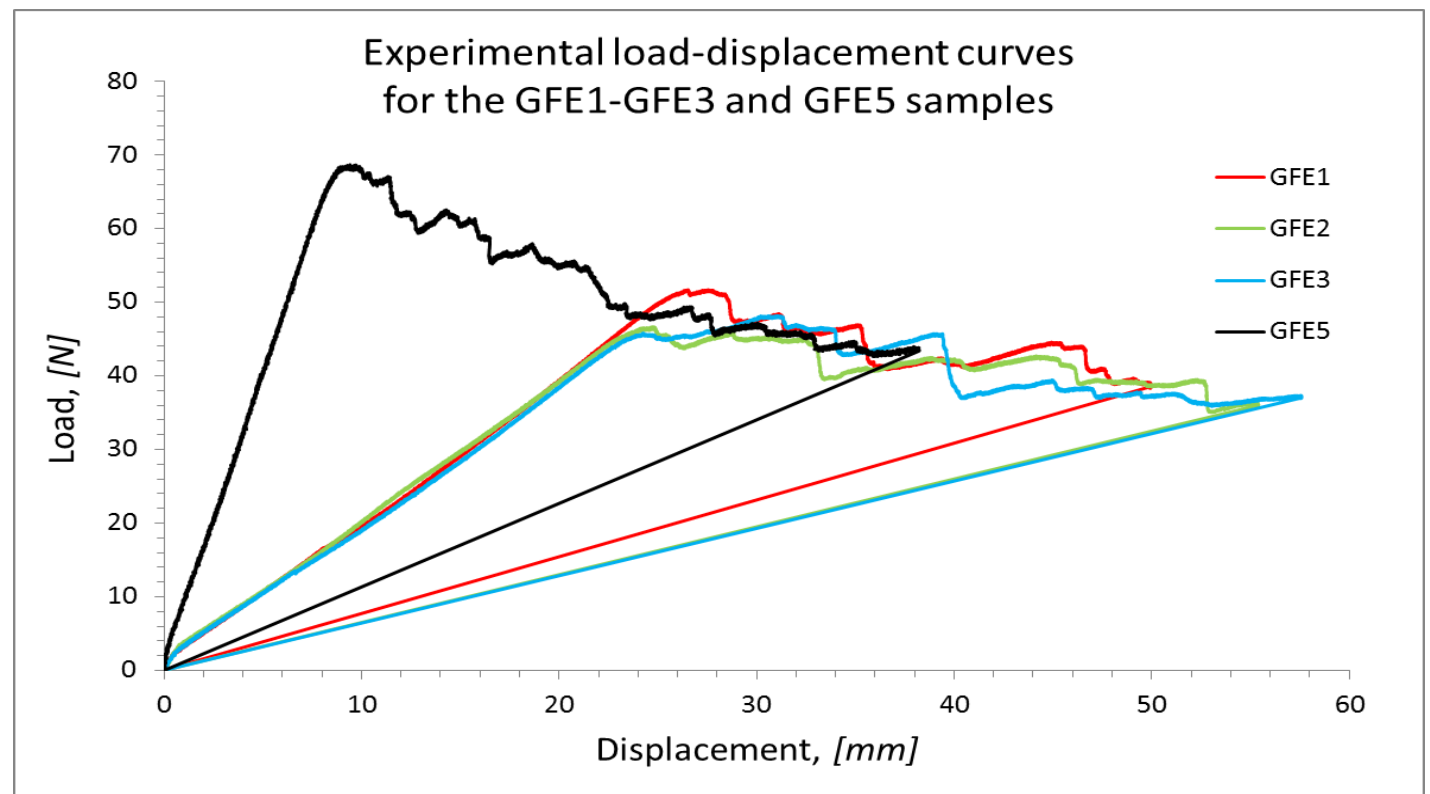

Fig 2 Load - Displacement curves for test specimens GFE1- GFE5

Conform to the procedure explained in the ASTM standard D5528, a mode I critical strain energy was calculated at initiation $\left(\mathrm{G}_{\mathrm{Ic} \text {, ini }}=0.961 \mathrm{~N} / \mathrm{mm}\right)$ and at propagation $\left(\mathrm{G}_{\mathrm{Ic} \text {, prop }}=1.125\right.$ 
$\mathrm{N} / \mathrm{mm}$ ) depending on the calculation method used viz. the modified beam theory (MBT), the compliance calibration (CC) and the modified compliance calibration (MCC), using following equations (2-4)):

$$
\begin{array}{lr}
\text { MBT: } & G_{I c}=\frac{3 P \delta}{2 b(a+\Delta)} \\
\text { CC: } & G_{I c}=\frac{n P \delta}{2 b a} \\
\text { MCC } & G_{I C}=\frac{3 P^{2} C^{2 / 3}}{2 A_{1} b h}
\end{array}
$$

where: $\mathrm{P}=$ load applied on the hinges, $[N]$

$\delta=$ load point deflection, $[\mathrm{m}]$

$\mathrm{b}=$ width of the test specimen, $[\mathrm{m}]$

$\mathrm{a}=$ total delamination length, $[\mathrm{m}]$

$\mathrm{C}=$ compliance, given by $\delta / \mathrm{P},[\mathrm{m} / \mathrm{N}]$

$\mathrm{h}=$ thickness of the test specimen, $[\mathrm{m}]$

$\Delta, \mathrm{n}, \mathrm{A}_{1}=$ correction factors, $[m],[-],[-]$

If the large displacements of the beam have to be taken into account, the critical energy release rates have to be multiplied with the correction factor $F$. With these equations, one can calculate the R-curves for the different test samples. An example of such a R-curve is given for test sample GFE3.

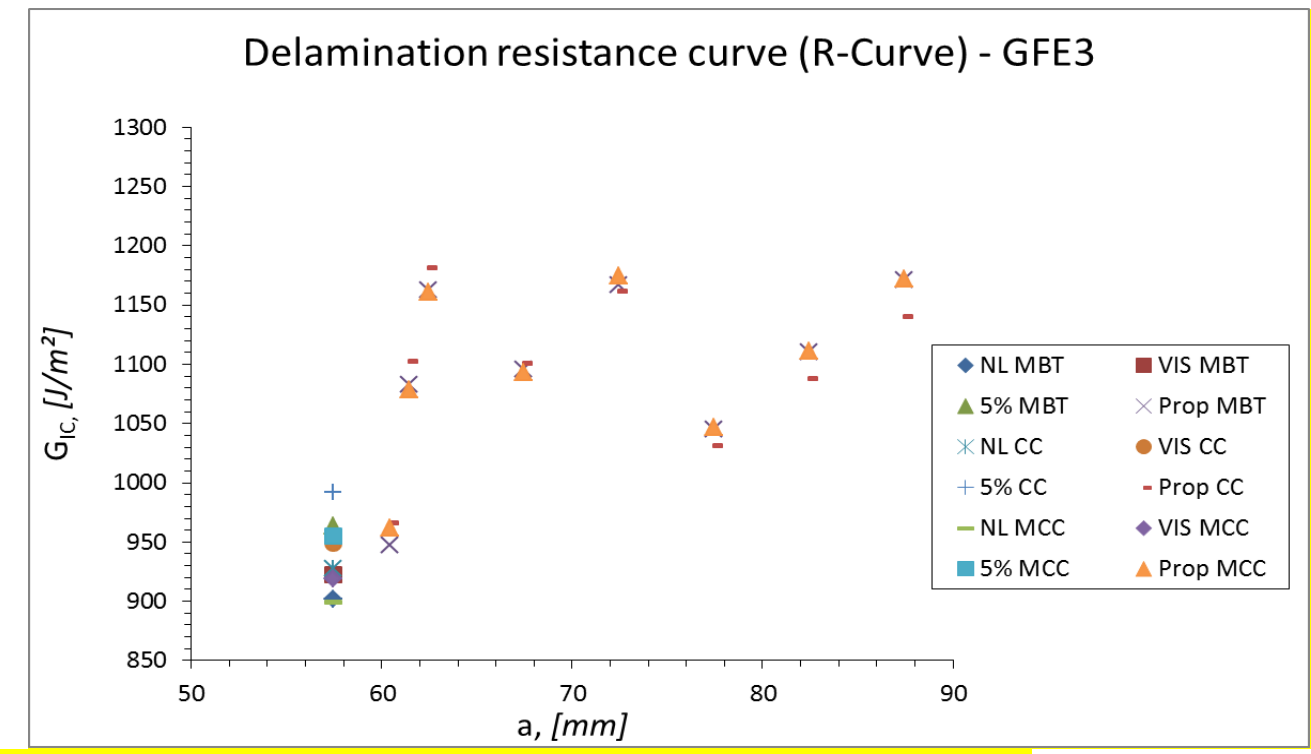

Fig 3: Delamination resistance curve (R-curve) for the GFE3 test specimen

A summarizing table of the obtained values for the critical strain energy release rat $G_{\text {Ic }}$ at initiation and propagation can be found in Fig 4. 


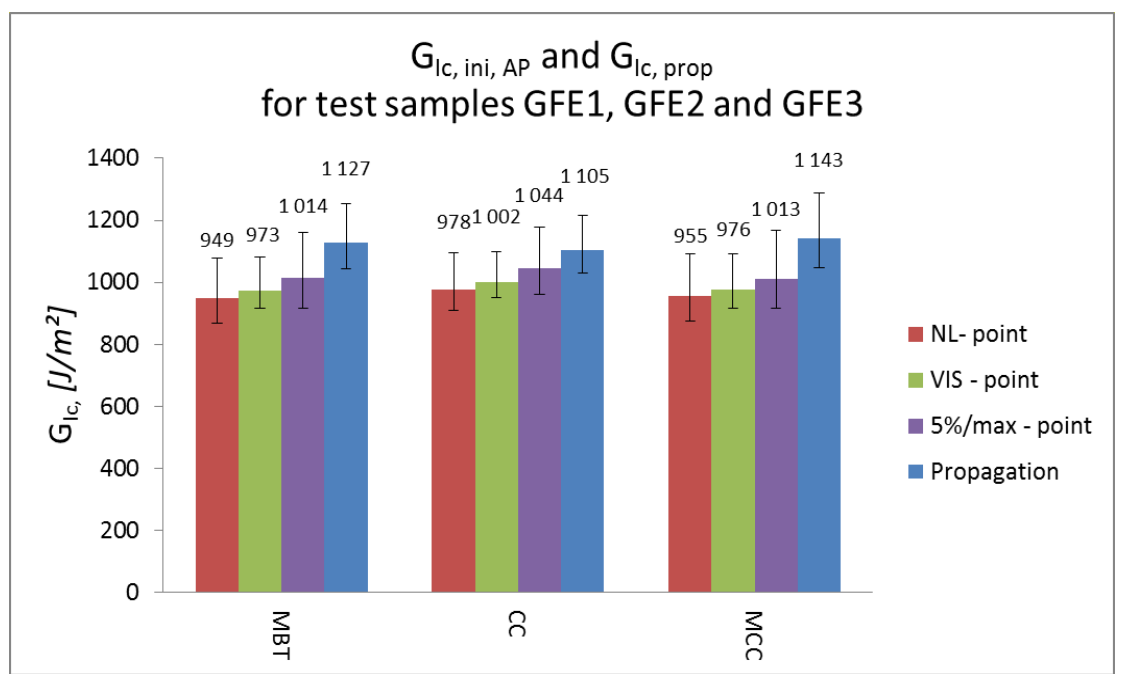

Fig 4: Resulting $\mathrm{G}_{\mathrm{Ic}}$ for test samples GFE1 - GFE3

It must be noted that the crack path could deviate from the centre of the DCB sample and a numerical investigation will be done concerning asymmetric substrate heights (4.2).

\section{CETEX}

The material used here is a polyphenylene sulphide (PPS) reinforced with a 5-harness satin weave carbon fibre (CF) fabric also known as CETEX. The plates with the insertion of a kapton film $(13 \mu \mathrm{m}$ thick $)$ in the midplane of the $\left[(0,90)_{4},(90,0)_{4}\right]_{\mathrm{s}}$ stacking exist of a total of 16 fabric layers. These plates were produced and delivered by TenCate (Netherlands). The plates were sawed using a diamond saw in the dimensions corresponding to the requirements given in the ASTM standard D5528 [25]. The elastic properties for the CETEX CF/PPS composite can be found in Table 4 and were obtained using a meso-scale homogenization as described in [26] as well as through experiments.

\begin{tabular}{|c|c|c|c|c|c|c|c|c|}
\hline \multicolumn{10}{|c|}{ CF/PPS (CETEX) } \\
\hline \multicolumn{10}{|c|}{ Elastic properties from meso-scale homogenization } \\
\hline $\begin{array}{c}E 11, \\
{[G P a]}\end{array}$ & $\begin{array}{c}E 22, \\
{[G P a]}\end{array}$ & $\begin{array}{c}E 33, \\
{[G P a]}\end{array}$ & $\begin{array}{c}v 12, \\
{[-]}\end{array}$ & $\begin{array}{c}v 13, \\
{[-]}\end{array}$ & $\begin{array}{c}v 23, \\
{[-]}\end{array}$ & $\begin{array}{c}G 12, \\
{[M P a]}\end{array}$ & $\begin{array}{c}G 13, \\
{[M P a]}\end{array}$ & $\begin{array}{c}G 23, \\
{[M P a]}\end{array}$ \\
\hline 56.2 & 56.21 & 10.66 & 0.08 & 0.42 & 0.42 & 4390.28 & 3227.19 & 3228.68 \\
\hline \multicolumn{10}{|c|}{ Elastic properties from experiments } \\
\hline $57 \pm 1$ & $57 \pm 1$ & - & $0.05 \pm 0.02$ & - & - & $4360 \pm 60$ & - & - \\
\hline
\end{tabular}

Table 4 Material properties used for the construction of the DCB model of the CETEX material

The dimensions of the test samples can be found in

\begin{tabular}{|c|c|c|c|}
\hline Specimen & Width, $[\mathrm{mm}]$ & $\mathrm{a}_{0}$ before pre-crack, $[\mathrm{mm}]$ & $\mathrm{a}_{0}$ after pre-crack, $[\mathrm{mm}]$ \\
\hline CET 1 & 22.5 & 48.3 & 52.0 \\
\hline CET 2 & 22.5 & 48.3 & 52.7 \\
\hline CET 3 & 22.5 & 47.8 & 55.1 \\
\hline CET 4 & 22.5 & 48.3 & 52.6 \\
\hline
\end{tabular}

Table 5 Dimensions of the cracks before and after pre-crack of test specimen CET 1 - CET 4

In Fig 5 all the force-displacement curves are shown, with (i) a continuous displacement of the crosshead of the tensile machine for test specimens CET 1 - CET 3 and (ii) a stepwise 
loading of test sample CET 4. CET 4 was loaded until crack propagation and unloaded sequentially until complete failure was achieved. The goal of the CET 4 experiment was to evaluate the effect of fibre bridging. By closing the specimen after each loading, any fibre bridging in the crack area is most likely crushed or buckled, hence eliminating the bridging force. The unloading of the test specimen CET 4 in Fig 5 is not shown for clarity purpose.

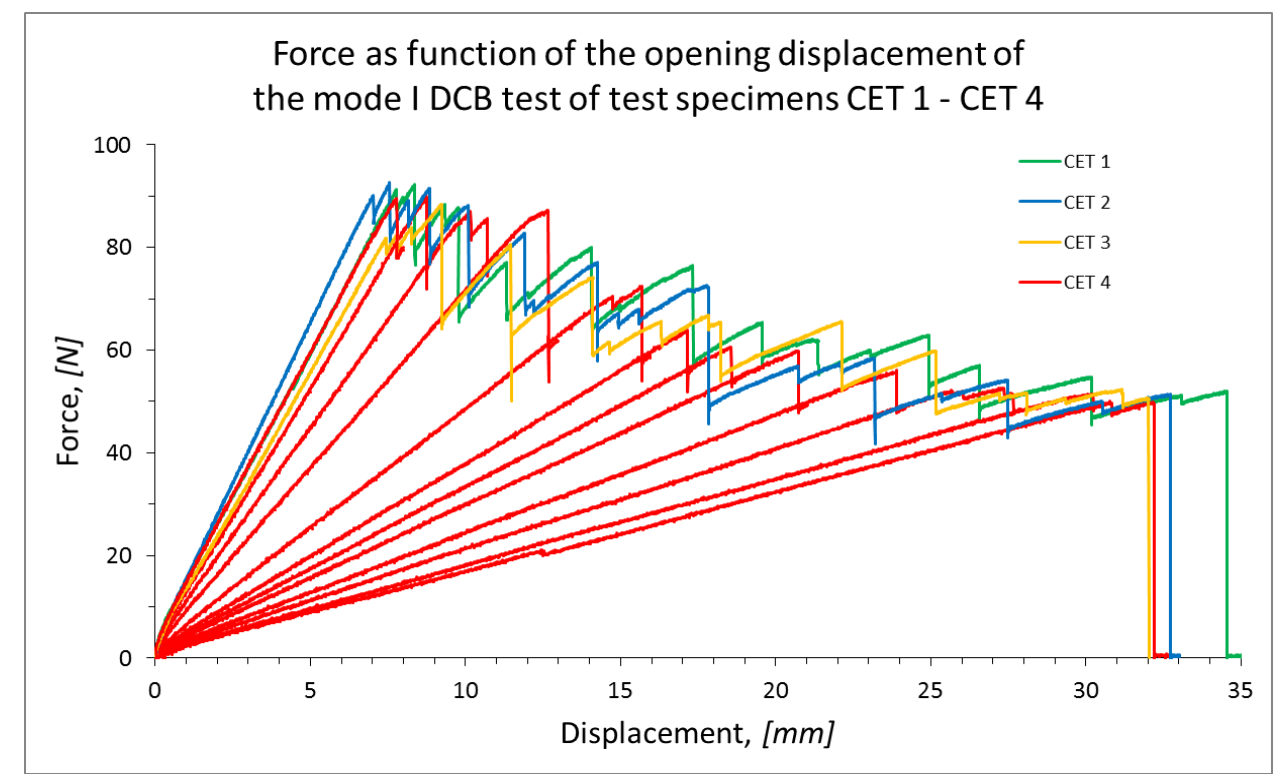

Fig 5: Force-displacement curves for the mode I DCB test for all the CETEX test specimens

A detailed procedure leading to the resulting critical energy release rates for mode I can be

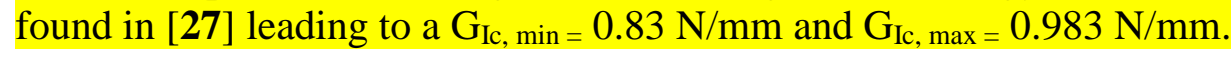

\subsubsection{Analytical solution for the mode I DCB test}

A lot of research has been effectuated on the analytical calculation of the mode I fracture toughness $\mathrm{G}_{\mathrm{Ic}}$. Multiple data reduction methods based on Linear Elastic Fracture Mechanics (LEFM) have been developed and can be categorized as: the compliance calibration methods based on experiments defining the relationship of the compliance versus the crack length $[28,29,30]$; the compliance calibration methods derived from the classical and modified beam theory [31,32,33]; an approach determining the energy release rate from the ratio of change in strain energy to the change in crack area $[33,34]$ and finally a reduction method using the $\mathrm{J}$ integral as a fracture parameter $[3,35]$. The expressions for $\mathrm{G}_{\mathrm{Ic}}$ used in this work are based on the work of Williams [31,36] and Hashemi et al. [33] leading to the equations below.

The necessary force $P$ for crack propagation is given by:

$$
P=\sqrt{\frac{G_{I c} b^{2} h^{3} E_{11}}{12(a+\chi h)^{2}}}
$$

where $\quad \mathrm{G}_{\mathrm{Ic}}=$ critical strain energy release rate, $[\mathrm{N} / \mathrm{m}]$

$\mathrm{b}=$ the width of the specimen, $[\mathrm{mm}]$

$\mathrm{h}=$ half of the thickness of the specimen, [mm]

$\mathrm{E}_{11}=$ longitudinal Young's modulus, $[\mathrm{Pa}]$

$\chi \mathrm{h}=$ compensation term for the crack tip rotation effect, [ $\mathrm{mm}]$

$\mathrm{a}=$ the length of the delamination, $[\mathrm{mm}]$ 
The corresponding displacement $\delta$ is given by:

$$
\delta=P \frac{8(a+\chi h)^{3}}{b h^{3} E_{11}}
$$

Eliminating $(a+\chi h)$ in equations (5) and (6), one obtains:

$$
P=\sqrt{8}\left(\frac{G_{I c}}{12}\right)^{\frac{3}{4}} \frac{1}{\sqrt{\delta}} b\left(h^{3} E_{11}\right)^{1 / 4}=f\left(G_{I c}\right) \delta^{-0.5}
$$

\subsection{Mode II - ENF}

The objective of an End Notch Flexural (ENF) test is to determine the $\mathrm{G}_{\text {IIc }}$ for an interlaminar interface. This test is not a standard yet, but the work item (ASTM WK22949) has been initiated in 2009 and still needs further development [37]. In the research community, a lot of research has been made on the determination of the mode II critical strain energy release $\mathrm{G}_{\text {IIc }}$ with the following three most popular experimental configurations: (i) the End Notch Flexure (ENF) test [38], (ii) the End Loaded Split (ELS) test [39,40] and (iii) the 4ENF test [41]. The ENF test is the simple three point bending test on a pre-cracked test specimen. A disadvantage of the ENF test method is the possibility of having unstable crack propagation. Referring to the work of Carlsson and Gillespie (1989) [40,41], the ENF test requires a ratio a/L > 0.7.

\subsubsection{Test setup}

All tests have been performed on the same electromechanical Instron 5800R tensile machine with a calibrated load cell of $1 \mathrm{kN}$ and the forces and displacements were recorded using the Blue Hill software throughout the experiment. The three rods, two supporting rods and one load introducing rod, have a diameter of $10 \mathrm{~mm}$.

\subsubsection{Material and results}

The same material as described in 3.1.2 was used. The dimensions of the test samples can be found in Table 6.

\begin{tabular}{|c|c|c|c|c|}
\hline Specimen & $\begin{array}{c}\text { Width, } \\
{[\mathrm{mm}]}\end{array}$ & $\begin{array}{c}\text { Half span L, } \\
{[\mathrm{mm}]}\end{array}$ & $\begin{array}{c}\text { Crack length } \mathrm{a}_{0}, \\
{[\mathrm{~mm}]}\end{array}$ & $\begin{array}{c}\text { Testing speed, } \\
{[\mathrm{mm} / \mathrm{min}]}\end{array}$ \\
\hline CET 7 & 16.1 & 100.0 & 70 & 0.5 \\
\hline CET 8 & 16.1 & 100.0 & 70 & 1 \\
\hline
\end{tabular}

Table 6 Dimensions of the CETEX test specimens (CET 7 - CET 8)

The load-displacement curves of the test samples CET 7 and CET 8 can be found in Fig 1 and show reproducible results. 


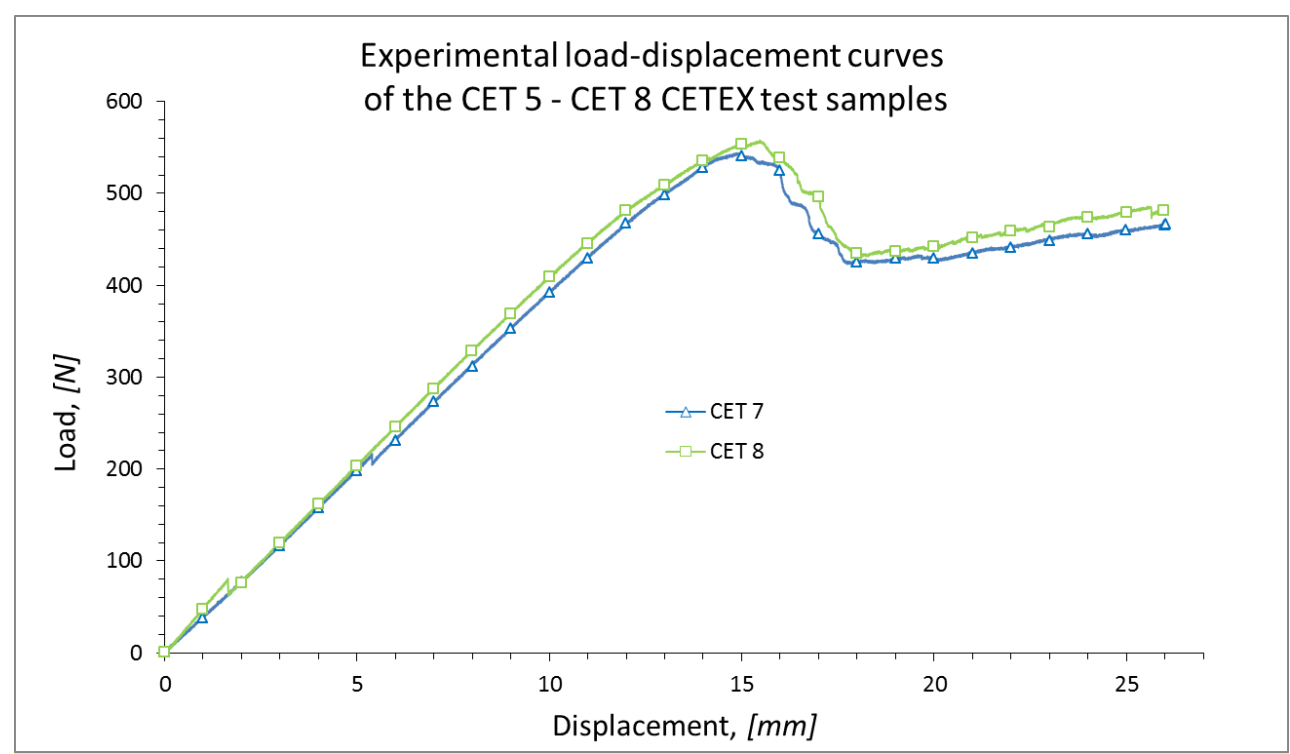

Fig 6: Force-displacement curves for the mode II DCB test for the CETEX test specimens

The procedure for the calculation of the Mode II $\mathrm{G}_{\text {IIc }}$ propagation $\left(\mathrm{G}_{\mathrm{IIc}, \text { prop }}\right)$ and its results can be found in [27] leading to an average $\mathrm{G}_{\text {IIc, prop }}=3400 \mathrm{~J} / \mathrm{m}^{2}$.

\subsubsection{Analytical solution for the mode II ENF test}

The analytical solution for the ENF test can be split in the three stages of the loaddisplacement curve as defined earlier [42]. The load and displacement can be calculated with following equations:

Linear part:

$$
\delta=\frac{P\left(3 a_{0}^{3}+2 L^{3}\right)}{8 E_{11} B h^{3}}
$$

Displacement and load during crack propagation with a $<\mathrm{L}$ :

$$
\begin{gathered}
\delta=\frac{P\left(3 a^{3}+2 L^{3}\right)}{8 E_{11} B h^{3}} \\
P=\sqrt{\frac{16 G_{I I c} B^{2} h^{3} E_{11}}{9 a^{2}}}
\end{gathered}
$$

Displacement and load during crack propagation with a $>$ L:

$$
\begin{gathered}
\delta=\frac{P}{2 E_{11} B h^{3}}\left[\begin{array}{c}
2 L^{3}-\frac{\left(\frac{16}{3} G_{I I C} E_{11} B^{2} h^{3}\right)^{3 / 2}}{4 \sqrt{3} P^{3}} \\
P=\sqrt{\frac{16 G_{I I C} B^{2} h^{3} E_{11}}{9 a^{2}}}
\end{array}\right]
\end{gathered}
$$

where: $\mathrm{G}_{\mathrm{IIc}}=$ critical mode II strain energy release rate, $\left[\mathrm{J} / \mathrm{m}^{2}\right]$ 
$\mathrm{B}=$ width of the test sample, $[\mathrm{m}]$

$\mathrm{h}=$ half of the thickness of the test sample, $[\mathrm{m}]$

$\mathrm{E}_{11}=$ longitudinal Young's modulus, $[\mathrm{Pa}]$

$\mathrm{P}=$ applied force, $[N]$

$\mathrm{a}=$ the crack length, $[\mathrm{m}]$

$\mathrm{L}=$ half of the span, $[\mathrm{m}]$

The last part of the analytical solution has not been proven, but it has been added here for completeness of the analytical expressions.

\section{Numerical simulations on the mode I - DCB}

A lot of research has been accomplished on this topic $[9,18,19,42,43,44,45]$ and many papers are related to the simulation of delaminations in a double cantilever beam test. But in many cases not all the different parameters are given in order to reproduce the same simulations using the same models and material parameters. Therefore, in following sections research has been done on all the different parameters having an impact on the finite element results, including the load-displacement curves.

\subsection{Parametric analysis}

\subsubsection{Numerical model}

The dimensions of the model studied here can be found in Fig 7 with a pre-crack $\mathrm{a}_{0}=40 \mathrm{~mm}$ and correspond to the models used by Turon et al in [10]. The same geometry has been used for both the 3D model using shell and solid elements. In order to simulate the motion of the hinges, the displacement has been introduced as given in Fig 7, where the sections representing the contact with the hinges are allowed to rotate and translate as it is in real life experiments.

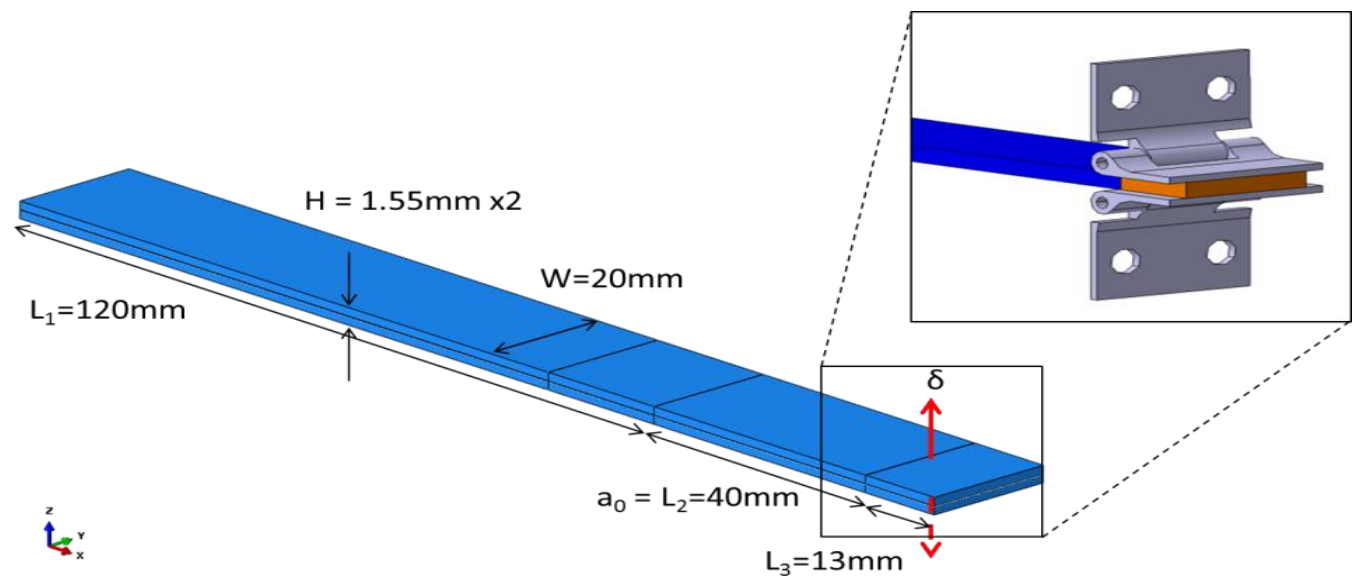

Fig 7: Geometrical dimensions of the DCB model used for the parametrical study

The load-displacement curves resulting from two numerical models, a 2D and a 3D as described below, will be compared to each other and to the analytical results calculated with the analytical solution for a DCB. The FE results were obtained taking into account the material properties given above and the geometrical properties (see section 3 ) as can be found in Fig 7 with following models:

- a 2D model with different types of elements and mesh densities

- a 3D model with different mesh densities and types of elements like for example shell elements and solid brick elements 
The delamination initiation and propagation are simulated by inserting a layer of cohesive elements in between the two substrates of the DCB test specimen. The different parameters impacting the results of numerical simulation of a DCB test will be proposed in following sections such as:

1. Stabilization method

2. Mesh

3. Output frequency of the data

4. Models (2D, 3D, shell, solid)

\subsubsection{Stabilization method}

In a finite element calculation a linear implicit analysis solves the linear part of the equation of motion:

$$
[K]\{u\}=\{F\}
$$

where $[\mathrm{K}]$ is the stiffness matrix, $\{\mathrm{u}\}$ is the displacement vector and $\{\mathrm{F}\}$ is the force vector. In this equation time does not play any role. Basically the objective of the solver is to find a solution for the load-displacement curve by solving a single system of linear equations. The standard implicit solver tries to calculate the equilibrium of the forces of the quasi-static analysis in all nodes as:

$$
F_{\text {ex }}-F_{\text {in }}=0
$$

where $F_{e x}$ are the external forces and $F_{\text {in }}$ are the internal forces resulting from the stress acting in the finite elements. This means that the internal forces and external forces will not be in equilibrium unless the stiffness is for the given step. However a non-linear analysis, like the simulation of a DCB test is, will generate convergence errors not leading to any results. Therefore a non-linear analysis is approached by specifying the load as function of time and it is incremented in order to obtain the non-linear response by correcting the displacements. Abaqus $^{\mathrm{TM}}$ segments the simulation into a number of time increments and searches for an acceptable solution for the equilibrium of forces at each time increment by using a Newton iteration to minimize the residual force vector. Therefore, in order to stabilize unstable quasistatic problems like the DCB test simulation, the software provides the following different mechanisms for the stabilization of the problem and used in this manuscript:

- Viscous regularization of the cohesive zone

- Automatic stabilization method

Basically both techniques will integrate a dashpot in the system in order to stabilize the unstable increments and thus stabilizing the dynamic effects due to the delamination of the substrates of the double cantilever beam. One big difference between both techniques is the fact that the viscous regularization is applied on an element set, whereas automatic stabilization is applied on the whole model. By using an adaptive damping factor, the software ensures that the ratio of the stabilization energy over the total strain energy does not exceed a user chosen accuracy tolerance. Often in literature the influence of these stabilization factors omitted. In Fig 8 the load-displacement curves are shown for varying damping factors of the viscous regularization method and for the automatic stabilization method. The 3D model consists of 6080 shell elements (S4) and 2520 cohesive elements (COH3D8) and with the material properties as given above, a stress based damage initiation was chosen with an energy based damage evolution method. 


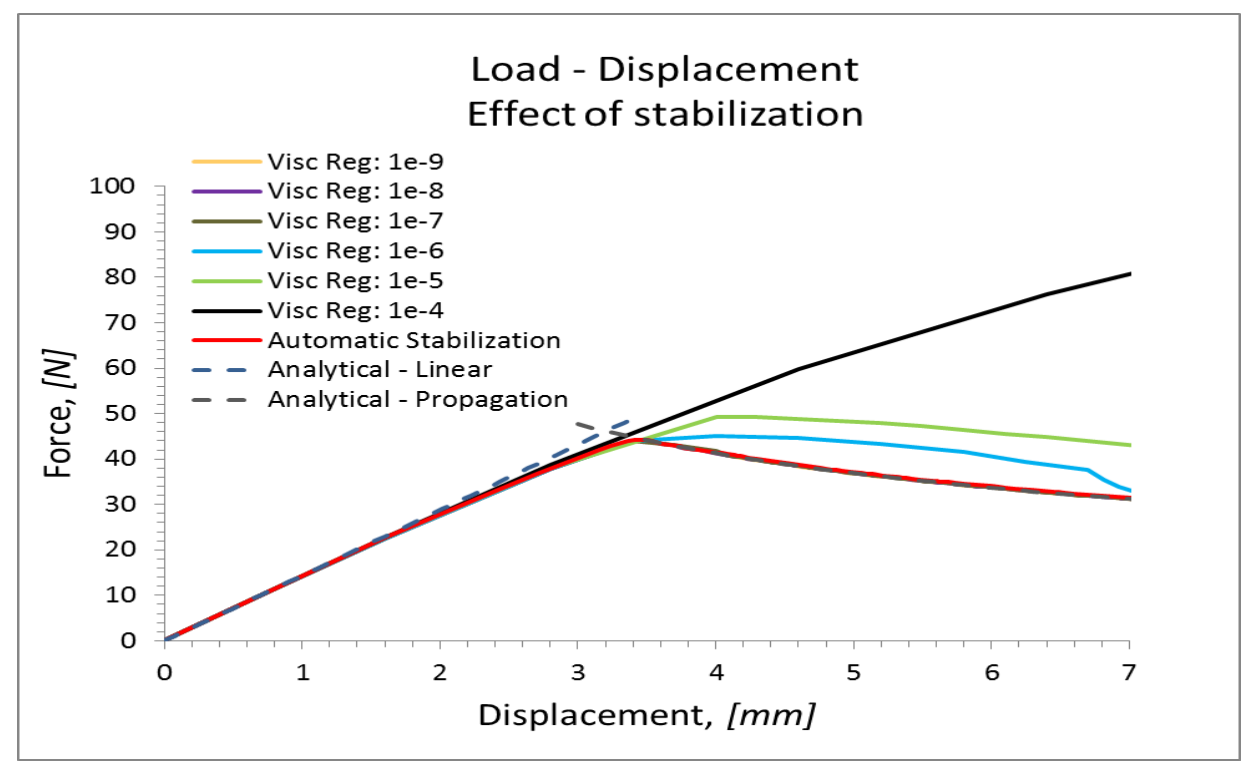

Fig 8 Effect of the stabilization on the load-displacement curve of a DCB test simulation

As can be seen in Fig 8, once the viscous regularization factor is sufficiently small $(<1 \mathrm{e}-7)$ the load-displacement curves are overlapping and converging, but from a certain order of magnitude (1e-6) it leads to inaccurate results. Therefore it is important to perform a convergence analysis for the viscous regularization factor. After each simulation an analysis of the dissipated energy over the total strain energy has to be made and this ratio has to remain under a tolerance $(<1 \%)$. The different dissipated energy ratio's and additionally the corresponding wall clock times needed for the calculation of the simulations can be found in Table 7. As can be seen the energy of the most accurate results with damping factors from 1e7 to $1 \mathrm{e}-9$ and the automatic stabilization lead to dissipated energy ratio's lower than $1 \%$ but for these models the needed calculation time increases drastically. The highest value for the calculation times is obtained for the automatic stabilization method which is as expected since the damping is applied to the entire model whereas by using the viscous regularization method, the damping is only applied to the selected element set. Therefore, for bigger simulations the viscous regularization method would lead to smaller calculation times, but a convergence study needs to be performed and therefore the automatic stabilization method could be as fast or faster. A script can be written in which initially the automatic stabilization method is used and after the first increment has been calculated, an estimation of the stabilization damping factor is obtained. If one reduces this obtained value a by factor of 10 , a good estimation of the viscous regularization factor could be obtained. For example, the initial damping factor for this given model using the automatic stabilization method is $6.46 \mathrm{e}-$ 7. So a good estimation for the viscous damping regularization factor would be $6.46 \mathrm{e}-8$.

\begin{tabular}{|c|c|c|c|c|c|c|c|}
\hline & \multicolumn{6}{|c|}{ Viscous regularization factor } & \\
\hline & $1 e-9$ & $1 \mathrm{e}-8$ & $1 e-7$ & $1 e-6$ & $1 e-5$ & $1 e-4$ & Auto Stab \\
\hline Wall clock, $[s]$ & 1298 & 800 & 855 & 330 & 184 & 62 & 1367 \\
\hline Max energy ratio, [\%] & 0.002 & 0.002 & 0.056 & 2.882 & 4.691 & 6.524 & 0.484 \\
\hline
\end{tabular}

Table 7 Maximum dissipated energy ratio's and wall clock times for different viscous regularization factors

\subsubsection{Output frequency of the results}

When describing the test method and test setup used in experimental studies, the researchers are expected to specify at which sample rate the data are captured and extracted. However when numerical simulations are described (except for linear elastic calculations) this 
specification is mostly not implemented in the manuscripts. But the output frequency will drive the virtual time steps of the calculation and thus the precision of the results. In Fig 9, the effect of different output frequencies on the load displacement curves are shown and it can be notified that the maximum force as well as the displacement at which the non-linearity initiates can vary. The model used for the calculations here is the same as the one used with automatic stabilization as proposed in previous section. Only the top of the load-displacement graph is shown (see scale of the $\mathrm{x}$ and $\mathrm{y}$ axis).

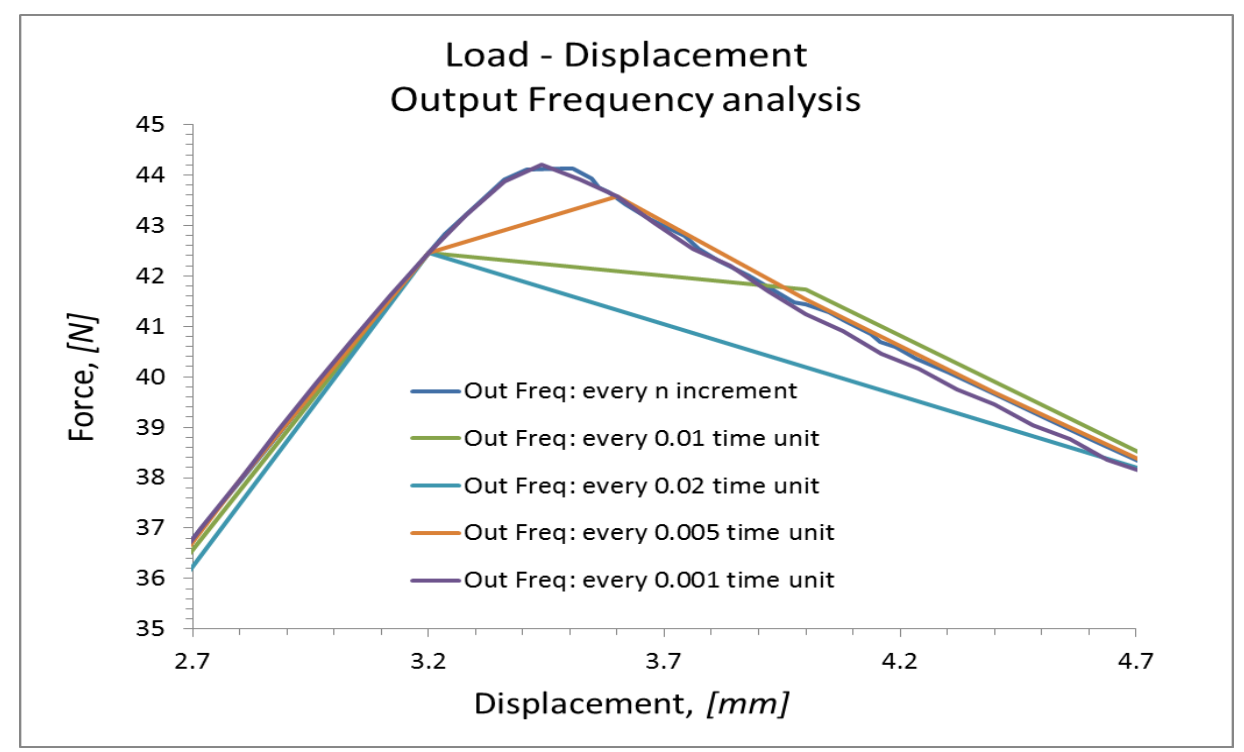

Fig 9 Effect of the output frequency on the load-displacement curve of a DCB test simulation

\subsubsection{Models}

When a numerical simulation has to be made, the engineers will try to approach the reality as closely as possible through the finite element results. A first important choice has to be made, viz. the type of model representing the part under the load conditions as defined in the experimental setup or under real loading conditions. This model in most cases has to be accurate and computationally efficient. In this work three different models representing the DCB test were studied and compared: (i) a 2D model; (ii) a 3D model consisting of shell elements and (iii) a 3D model consisting of solid brick elements.

For these three models different finite element mesh types were used like: linear shell elements, quadratic shell elements, linear solid elements and linear plane stress elements. The impact of the different mesh types and sizes will be presented in the next section (4.1.5).

The 3D solid model exists of 34600 linear hexahedral elements for the substrates and 2400 cohesive elements for a total amount of 55668 nodes. Each substrate has 4 elements through the thickness. The 3D shell model is the same as the one used in the previous sections and consists of 6080 shell elements (S4) and 2520 cohesive elements (COH3D8). The 2D model was built up with 7970 linear quadrilateral elements (CPS4I) with 800 cohesive elements linking both substrates. The CPS4I element in Abaqus is an incompatible mode first order element adding incompatible deformation modes internally to the element avoiding the element being too stiff (due to shear stresses) in bending. A good correlation between the three models is achieved, but of course the calculation times, depending on the mesh size, increase from $2 \mathrm{D}$ to $3 \mathrm{D}$ shell to $3 \mathrm{D}$ solid model since there are more nodes and integration points.

\subsubsection{Mesh}

Another important parameter to study when dealing with damage simulations is the impact of the finite element mesh on the results. Effects of the mesh size of the finite element model 
including the cohesive elements can be found in different literature as for example in [46]. But it will be shown that it is more the combination of all the different parameters that have an impact on the results instead of the parameters individually. All the different models trying to predict the length of the cohesive zone have the form [46]:

where $\mathrm{E}$

$$
l_{F P Z}=M_{F P Z} E \frac{G_{C}}{\left(\tau^{0}\right)^{2}}
$$

$\tau^{0} \quad=$ maximum interfacial strength

$M_{F P Z} \quad=$ Parameter depending on the cohesive zone model

$\mathrm{G}_{\mathrm{c}} \quad=$ critical strain energy release rate

Dugdale and Barenblatt [7,8] estimated the cohesive length of the fracture process zone (FPZ) for an elastic-plastic solid and a brittle material respectively. Others like Hui et al., Irwin, Rice and Falk, Hilleborg et al. [46] obtained for different materials similar expressions with a different $\mathrm{M}_{\mathrm{FPZ}}$ (varying from 0.21 to 1 ) and these expressions were generalized in equation (15) by Camanho and Turon [46]. For slender substrates with constitutive models having nonzero tractions when the displacement jump is zero, the characteristic length can be calculated as [47]:

$$
l_{F P Z}=\left[E \frac{G_{c}}{\left(\tau^{0}\right)^{2}}\right]^{1 / 4} t^{3 / 4}
$$

The number of elements in the FPZ can be calculated as:

$$
N_{e}=\frac{l_{F P Z}}{l_{e}}
$$

where $l_{e}$ is the length of a finite element of a mesh in the direction of the crack propagation. In literature $[46,48]$ one can find a lot of different minimum lengths of the cohesive element mesh needed in the fracture process zone, going from 2 to more than 10 elements in the cohesive zone. However it is not always that obvious, since it is the combination of the different parameters which result in an accurate set of FE results. Here the influence of the length of the cohesive elements as well as the influence of the length of the continuum mesh will be analysed. Considering the material properties given in section 3.1 and considering both equations (15) and (16) one calculates the minimum length of the cohesive zone as given in Table 8:

\begin{tabular}{|c|c|c|c|}
\hline \multicolumn{5}{|c|}{ General } \\
\hline$\tau_{0},[\mathrm{MPa}]$ & $\mathrm{N}_{\mathrm{e}}$ & $1_{\mathrm{FPZ},}[\mathrm{mm}]$ & $1_{\mathrm{e}},[\mathrm{mm}]$ \\
\hline 15 & 4 & 10.72 & 2.68 \\
\hline 60 & 4 & 0.67 & 0.17 \\
\hline \multicolumn{4}{|c|}{ Slender } \\
\hline$\tau_{0,[\mathrm{MPa}]}$ & $\mathrm{N}_{\mathrm{e}}$ & $1_{\mathrm{FPZ}},[\mathrm{mm}]$ & $1_{\mathrm{e}},[\mathrm{mm}]$ \\
\hline 15 & 4 & 2.59 & 0.65 \\
\hline 60 & 4 & 1.30 & 0.32 \\
\hline
\end{tabular}

Table 8 Length of the cohesive zone and cohesive elements in the FPZ

The most used values for $\mathrm{M}_{\mathrm{FPZ}}$ are the ones described by Rice and Falk $\left(\mathrm{M}_{\mathrm{FPZ}}=0.88\right)$ and Hilleborg et al. $\left(\mathrm{M}_{\mathrm{FPZ}}=1\right)$ [10]. Table 8 shows that with $\mathrm{M}_{\mathrm{FPZ}}=0.88$ and a strength $\tau_{0}$ of $15 \mathrm{MPa}$ a cohesive zone length of $10.7 \mathrm{~mm}$ would be obtained using the general method leading to a cohesive element length $1_{\mathrm{e}}$ of $2.7 \mathrm{~mm}$ (when using 4 elements in the FPZ). For the same strength and the same number of elements in the FPZ $\left(\mathrm{N}_{\mathrm{e}}=4\right)$ but by applying the 
equation for slender bodies (equation (16)) one obtains a cohesive element mesh length $1_{\mathrm{e}}$ of $0.65 \mathrm{~mm}$. This strength of $15 \mathrm{MPa}$ will be used in the 2D and 3D models.

\section{D models}

In order to study the effect of the mesh refinement of the cohesive elements, several simulations were produced for different mesh sizes of the cohesive elements and with constant mesh for the substrates of the DCB model. The output frequency of the results corresponds to each calculated time increment (automatically defined by the solver). Fig 10 shows the load-displacement results for the 2D numerical model consisting of 9170 mesh elements (with an element length of $0.15 \mathrm{~mm}$ in the FPZ) for the substrates with increasing number of cohesive elements as can be found in the figure. The numerical models were calculated with viscous regularization (= VIS in the names of the curves). The model with a fine mesh length of $0.25 \mathrm{~mm}$ already shows an accurate solution compared to the analytical solution. But the model with a mesh length of $1 \mathrm{~mm}$ did not give any error with also a good correlation regarding the elastic part and the propagation part of the graph, but not capturing the correct force during the initiation of the crack. Therefore it is important to check the results in an adequate manner, since if one only would base on the energies and have an automatic optimization by fitting the FE results on the analytical solution, an error of around $15 \%$ on the maximum force would not have been seen. From a cohesive element length of $0.65 \mathrm{~mm}$ the results are getting very close to the analytical solution and the finer the mesh, the smoother the load-displacement curve. The elastic part of the curve shows some deviation when compared to the analytical, but this can be improved by changing the strength parameter. One can see that a mesh size corresponding to the size predicted by the slender body equation (16) shows already good correlation by using 4 elements in the FPZ, but a smooth result is obtained with finer meshes. However when applying a high output frequency and thus inducing small time increments for the calculation of the numerical results, the loaddisplacement curve of the model using $1 \mathrm{~mm}$ cohesive elements gives a good correlation with the analytical results (see model " $2 \mathrm{D}-1 \mathrm{~mm}$ Coh mesh - VIS - Output $=0.001$ " in Fig 10). This means that a good combination of parameters is important. By increasing the strength $\tau_{0}$, the size of the cohesive element will decrease quite drastically leading to very fine meshes and high calculation times.

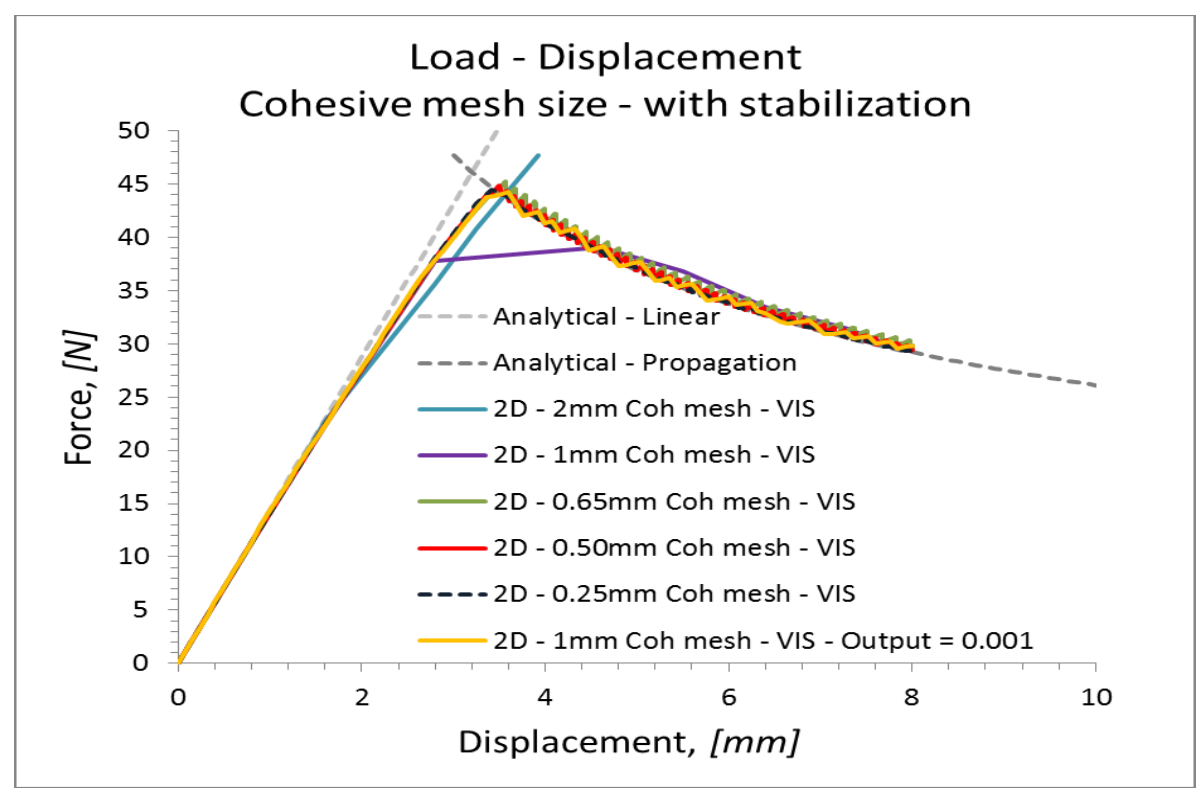

Fig 10 Cohesive mesh size influence on the load-displacement results with stabilization $-\tau_{0}=15 \mathrm{MPa}$ 
When keeping the cohesive element length constant and with mesh refinement of the mesh of the substrates, one obtains the load-displacement solutions as given in Fig 11. As can be seen the mesh has an influence on the stability of the calculation. It can be seen that it is recommended to have smaller cohesive element lengths compared to the "regular" mesh, since instabilities can occur (see model B in Fig 11). But when the substrates' mesh is too big (e.g. $>1 \mathrm{~mm}$ ), the simulation results diverge when keeping the stabilization identical to lower mesh sizes.

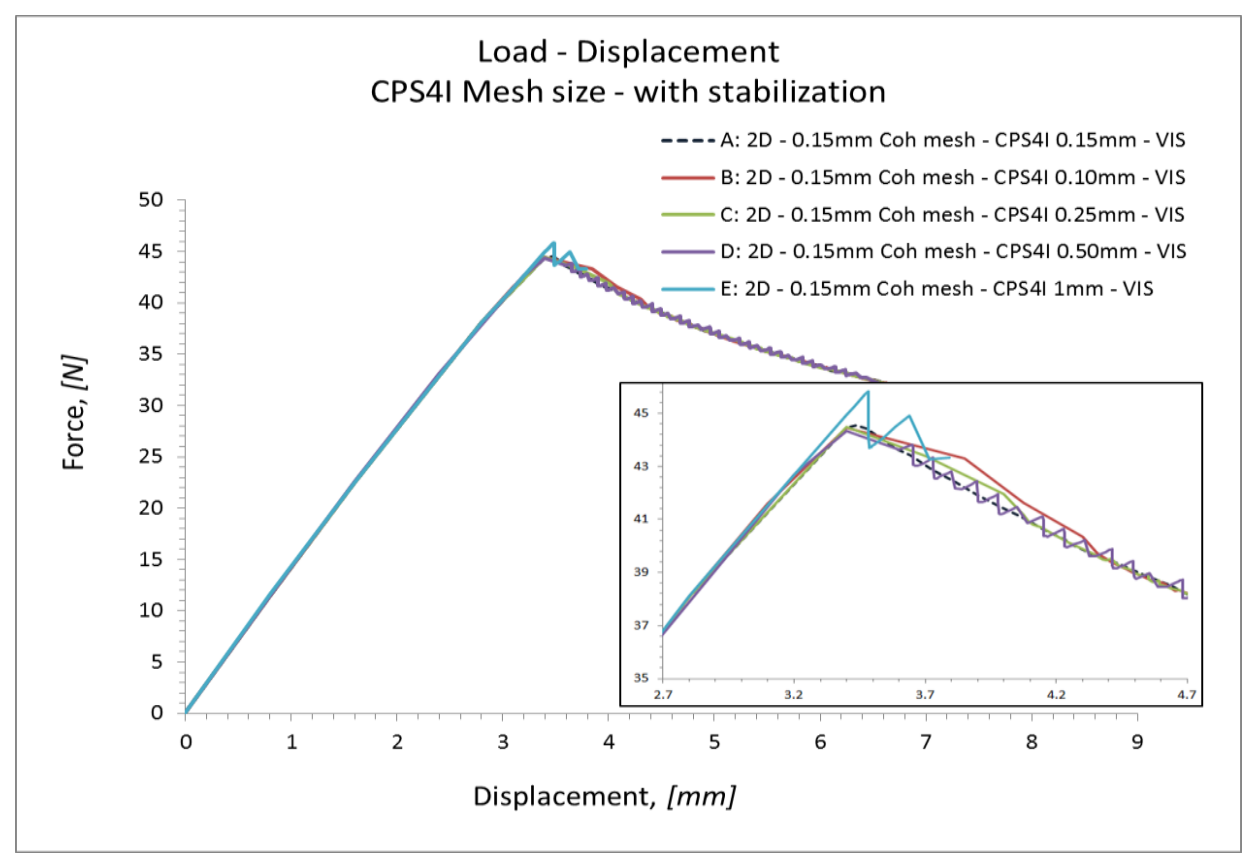

Fig 11 Mesh influence of the substrates with constant cohesive mesh length

In Fig 12 the load-displacement curves are shown for different cohesive and regular mesh elements combinations. For a model consisting of exactly the same mesh for both the cohesive elements mesh and the mesh of the substrates, the stabilization factor had to be refined (from 1e-7 (model A) to 1e-8 (model B)) in order to obtain a representative loaddisplacement curve. After a displacement of $3.8 \mathrm{~mm}$ for model A the solution of the calculation was diverging and stopped. The same happened for model B, but at a displacement of $6 \mathrm{~mm}$. Model $\mathrm{D}$ and $\mathrm{E}$ show the influence of having multiple elements through the thickness with only one element per substrate for model D and four elements in the thickness direction for model E. One can conclude that for different meshes, it is important to check the results, the load-displacement curves and the energies in the model. Obtaining converged solutions is not a guarantee for having accurate results, and multiple parameters influence this like the mesh density in the longitudinal direction as well as through the thickness, the corresponding mesh nodes between the cohesive elements and the regular mesh. But also the combinations between different parameters like the mesh and stabilization. 


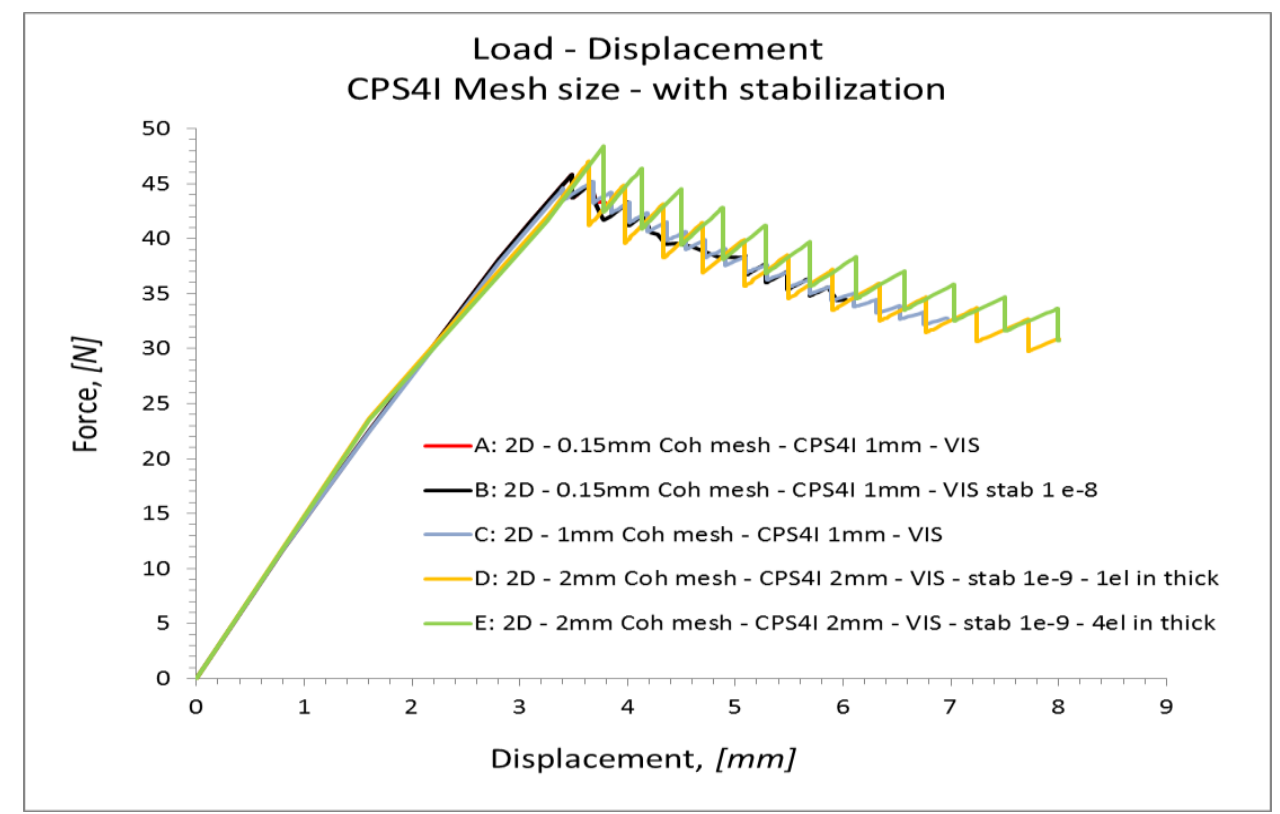

Fig 12 Influence of the mesh elements combinations on the load-displacement curves

$\underline{3 \mathrm{D} \text { models }}$

In a simulation of a realistic part or assembly, mostly 3D models will have to be calculated. Therefore some mesh influence analysis was performed on a 3D shell and a 3D solid model. In Table 9 the different 3D models used for the modelling of the DCB are presented. All the 3D models were calculated using the automatic stabilization method with an output of the required parameters at each time increment. Three models (Quad Solid 1,2 and 3 in the ID column of Table 9) were built with quadratic elements based on the same mesh as the equivalent linear element models (Linear Solid 1, 2 and 3).

\begin{tabular}{|c|c|c|c|c|c|c|}
\hline & ID & Type & Order & Number & $\begin{array}{c}\text { Length in } \\
\text { longitudinal dir, } \\
{[\mathrm{mm}]}\end{array}$ & $\begin{array}{c}\text { number of el. through } \\
\text { the thickness }\end{array}$ \\
\hline \multirow{10}{*}{ shell } & \multirow{2}{*}{ Linear Shell 1} & S4 & 1 & 3460 & 0.5 & 1 \\
\hline & & $\mathrm{COH} 3 \mathrm{D} 8$ & 1 & 1200 & 0.5 & 1 \\
\hline & \multirow{2}{*}{ Linear Shell 2} & S4 & 1 & 6920 & 0.5 & 1 \\
\hline & & COH3D8 & 1 & 2400 & 0.5 & 1 \\
\hline & \multirow{2}{*}{ Linear Shell 3} & S4 & 1 & 6920 & 0.25 & 1 \\
\hline & & $\mathrm{COH} 3 \mathrm{D} 8$ & 1 & 2400 & 0.25 & 1 \\
\hline & \multirow{2}{*}{ Quad Shell 1} & S8 & 2 & 1730 & 1 & 1 \\
\hline & & $\mathrm{COH} 3 \mathrm{D} 8$ & 1 & 1200 & 0.5 & 1 \\
\hline & \multirow{2}{*}{ Quad Shell 2} & S8 & 2 & 3460 & 0.5 & 1 \\
\hline & & $\mathrm{COH} 3 \mathrm{D} 8$ & 1 & 1200 & 0.5 & 1 \\
\hline \multirow{8}{*}{ Solid } & \multirow{2}{*}{ Linear Solid 1} & C3D8 & 1 & 3460 & 1 & 4 \\
\hline & & $\mathrm{COH} 3 \mathrm{D} 8$ & 1 & 1200 & 0.5 & 1 \\
\hline & \multirow{2}{*}{ Linear Solid 2} & C3D8 & 1 & 6920 & 0.5 & 4 \\
\hline & & $\mathrm{COH} 3 \mathrm{D} 8$ & 1 & 1200 & 0.5 & 1 \\
\hline & \multirow{2}{*}{ Linear Solid 3} & C3D8 & 1 & 13840 & 0.25 & 4 \\
\hline & & $\mathrm{COH} 3 \mathrm{D} 8$ & 1 & 2400 & 0.25 & 1 \\
\hline & \multirow{2}{*}{ Linear Solid 4} & C3D8 & 1 & 17300 & 0.5 & 10 \\
\hline & & $\mathrm{COH} 3 \mathrm{D} 8$ & 1 & 1200 & 0.5 & 1 \\
\hline \multirow{2}{*}{ Solid } & \multirow{2}{*}{ Linear Solid 5} & C3D8 & 1 & 34600 & 0.25 & 10 \\
\hline & & $\mathrm{COH} 3 \mathrm{D} 8$ & 1 & 2400 & 0.25 & 1 \\
\hline
\end{tabular}




\begin{tabular}{|l|c|c|c|c|c|}
\hline \multirow{2}{*}{ Quad Solid 1 } & C3D20 & 2 & 3460 & 1 & 4 \\
\cline { 2 - 6 } & COH3D8 & 1 & 1200 & 0.5 & 1 \\
\hline \multirow{2}{*}{ Quad Solid 2 } & C3D20 & 2 & 6920 & 0.5 & 4 \\
\cline { 2 - 6 } & COH3D8 & 1 & 1200 & 0.5 & 1 \\
\hline \multirow{2}{*}{ Quad Solid 3 } & C3D20 & 2 & 13840 & 0.25 & 4 \\
\cline { 2 - 6 } & COH3D8 & 1 & 2400 & 0.25 & 1 \\
\hline \multirow{2}{*}{ Quad Solid 4 } & C3D20 & 2 & 20232 & $0.25^{*}$ & 4 \\
\cline { 2 - 6 } & COH3D8 & 1 & 2400 & 0.25 & 1 \\
\hline \multirow{2}{*}{ Quad Solid 5 } & C3D20 & 2 & 40464 & $0.25^{*}$ & 8 \\
\cline { 2 - 6 } & COH3D8 & 1 & 2400 & 0.25 & 1 \\
\hline
\end{tabular}

Table 9 Mesh properties for multiple shell and solid element models with cohesive elements

The *-sign describing the length in the longitudinal direction for models "Quad Solid 4" and "Quad Solid 5" means that the mesh was created with a concentration of a fine mesh $(0.25$ $\mathrm{mm}$ ) in the part where the crack propagates and with a coarser mesh outside this zone. In Fig 13 the results of the load-displacement curves obtained during a mesh convergence analysis are shown. Since linear solid elements do not have rotational degrees of freedom, the curve obtained with model E (see Fig 13), existing of 10 elements through the thickness, approaches more accurately the analytical prediction than model A existing of 2 elements through the thickness as expected. This is logic since the more elements through the thickness, the better the rotations of the substrates can be captured.

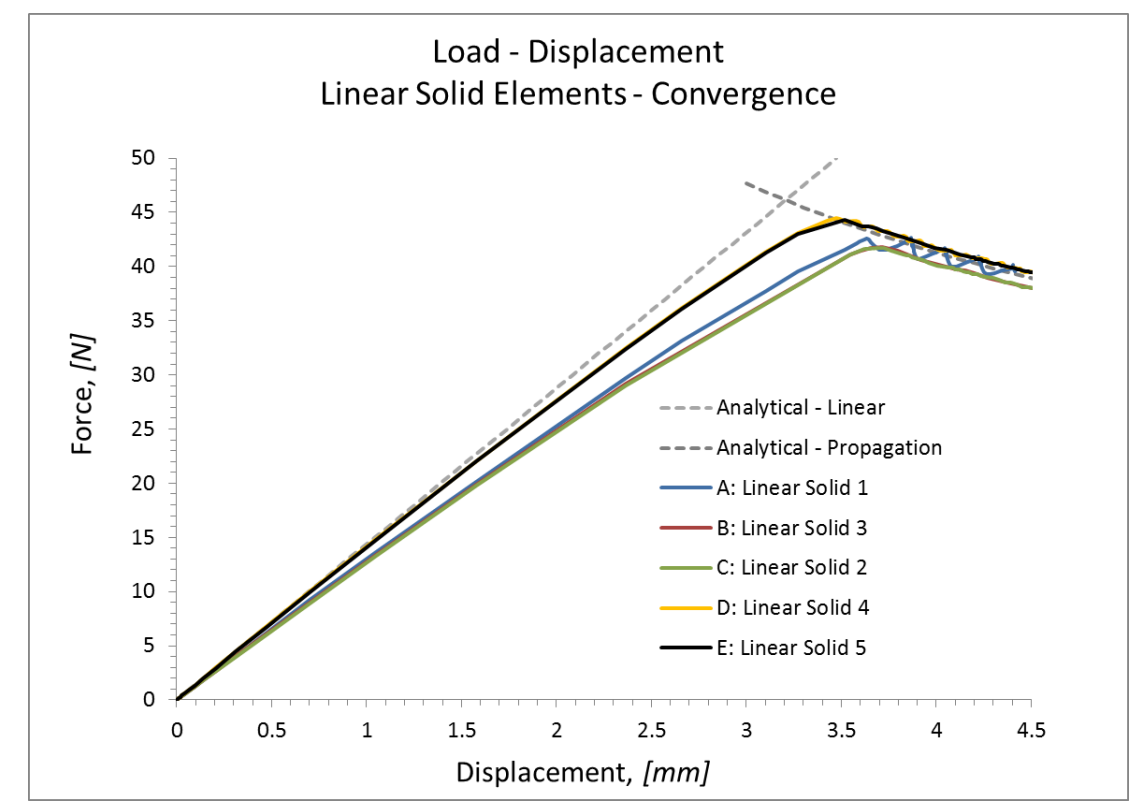

Fig 13 Mesh convergence results for the linear solid elements

When comparing the linear solid element numerical models to their quadratic equivalent (Fig 14), meaning an additional number of degrees of freedom, and thus a more accurate approach of the reality, it is obvious that a sufficient amount of degrees of freedom through the thickness will lead to more precise results. Of course the time needed for obtaining a solution increases drastically with increasing degrees of freedom. 


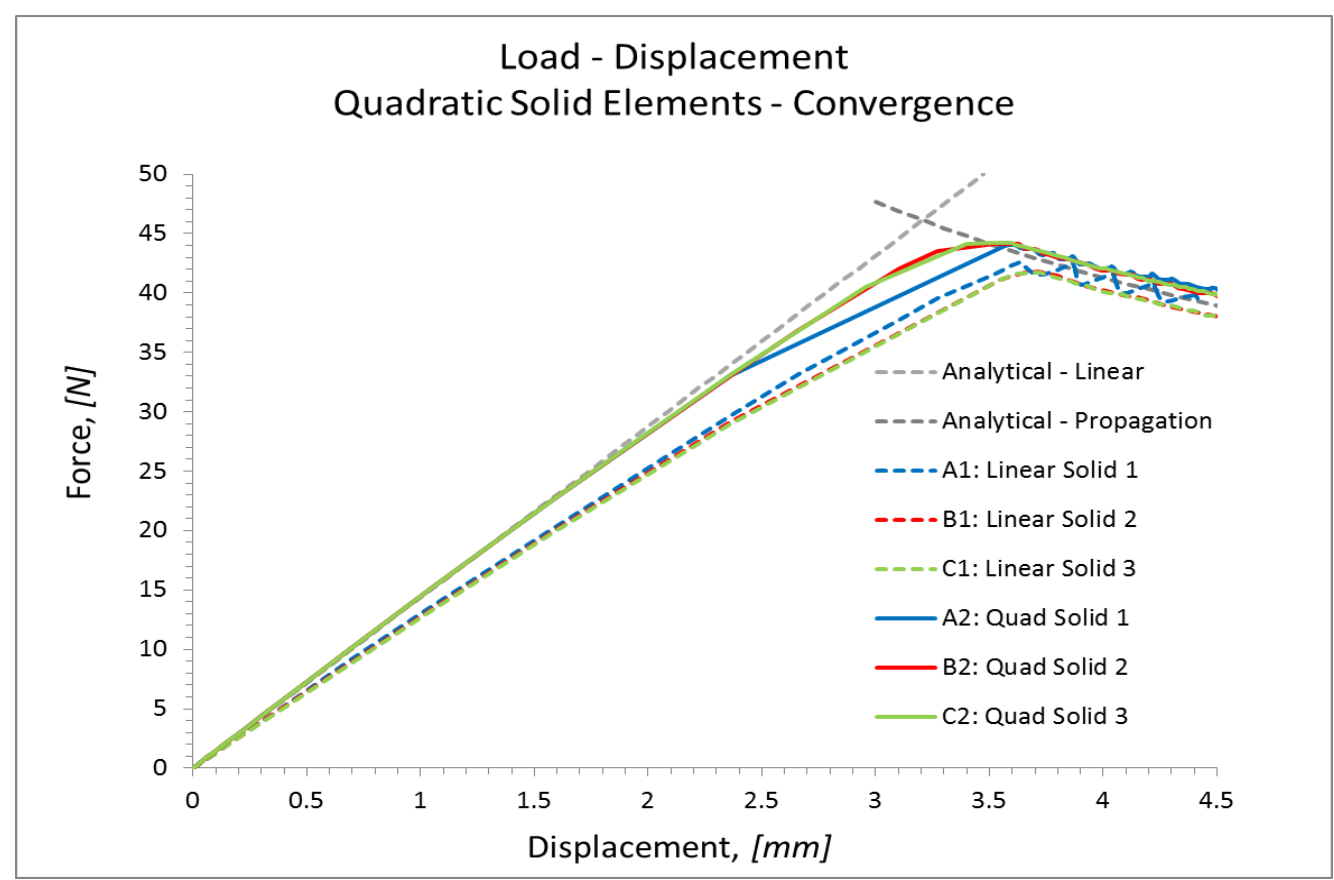

Fig 14 Mesh convergence results for the quadratic solid elements with comparison with the equivalent linear element models

A similar study for the quadratic elements was performed on the accuracy of the results due to the increasing number of degrees of freedom in the thickness direction allowing a smooth bending of the individual substrates of the DCB test model. If the number of elements is too low, the bending will not be represented ideally and the bending stiffness will be overestimated. This overestimation will be cumulated and for higher displacements the numerical load-displacement results will tend to diverge from the analytically predicted values. Of course it is the number of degrees of freedom which is important, since for a fine mesh (10 elements) with linear elements through the thickness equivalent results will be obtained with a coarser mesh but with higher order elements. Ideally a convergence test has to be performed in order to reduce the mesh effects on the results.

The same analysis can be made for the 3D shell model with linear and quadratic elements. In Table 9 one can see that models "Linear Shell 2" and "Linear Shell 3" are built up with the same amount of finite element mesh elements, but the elements of model "Linear Shell 2" are bigger than for model "Linear Shell 3". This is because model "Linear Shell 2" has more elements in the width direction compared to the other model. Basically the same conclusions can be made as for the solid brick elements concerning the number of degrees of freedom leading to more accurate results.

\subsubsection{Strength}

If a closer look is taken at Fig 10 one notices the difference between the analytically calculated peak force and the simulated peak force. A parameter which can influence this, is the maximum strength chosen in the traction-separation law $\tau_{0}$. The influence of this strength on the load-displacement curves, keeping all other parameters unchanged, can be found in Fig 15. The linear elastic part of the curve becomes stiffer and the force at crack initiation increases with the increasing strength parameter $\tau^{0}$ from $15 \mathrm{MPa}$ to $60 \mathrm{MPa}$. A side effect when changing the value of this parameter, which also happened when changing the mesh parameters, is that when using viscous regularization, the stability factor needed to be adapted in order to obtain a converged solution. With higher strength values, one approaches the 
analytical values almost perfectly, but the solution tends to diverge. Therefore in a damage initiation and propagation analysis on a real life design part, a trade-off will have to be made concerning the choice of the parameters. Alfano and Crisfield (2001) [19] stipulated that changing the maximum interfacial strength does not have a big influence on the delamination propagation results, and lower strengths improve the convergence of the results. Therefore the technique used the most for obtaining the maximum strength nowadays is by optimizing the parameter by comparing the numerical load-displacement results and the experimentally obtained results. It has only a small influence on the DCB results regarding the loaddisplacement graphs, but it can have quite a big influence on the total behaviour due to the stiffness changes, especially in the mode II simulations.

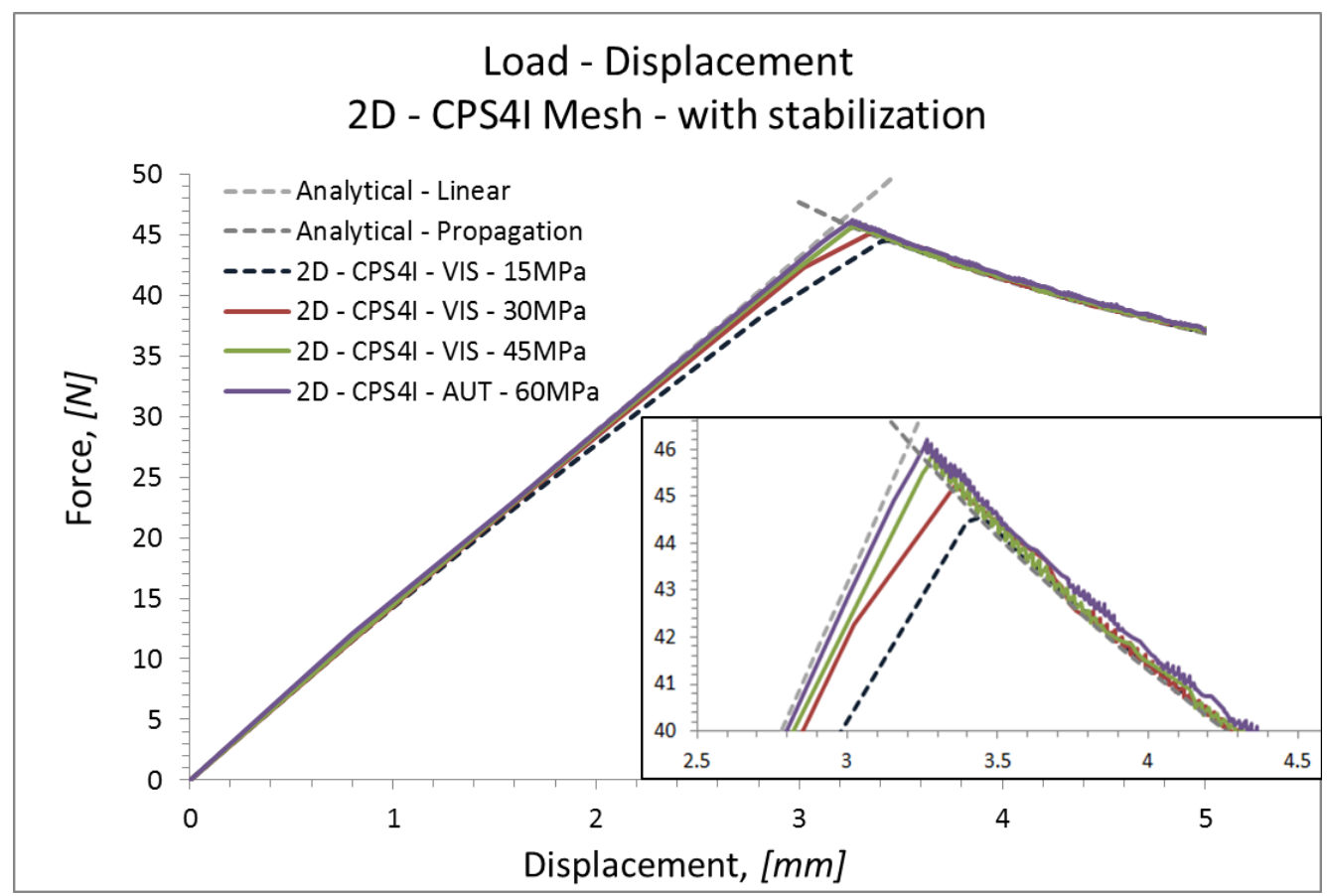

Fig 15 Influence of the strength parameter $\tau_{0}$ of the traction separation law on the load-displacement results

\subsubsection{Stiffness}

The last parameter in the constitutive definition of the traction separation law with an influence on the simulated load-displacement curves is the stiffness. Considering an increase of the stiffness $K$ from $1 \mathrm{e} 0 \mathrm{~N} / \mathrm{mm}^{3}$ to $1 \mathrm{e} 9 \mathrm{~N} / \mathrm{mm}^{3}$, the obtained simulated results are shown in Fig 16. For a stiffness beneath a minimum threshold and above a maximum threshold the results are converging but far from the analytical prediction, for example for $\mathrm{K}=1 \mathrm{e} 0 \mathrm{~N} / \mathrm{mm}^{3}$, $\mathrm{K}=1 \mathrm{e} 1 \mathrm{~N} / \mathrm{mm}^{3}, \mathrm{~K}=1 \mathrm{e} 8 \mathrm{~N} / \mathrm{mm}^{3}$ and $\mathrm{K}=1 \mathrm{e} 9 \mathrm{~N} / \mathrm{mm}^{3}$. The penalty stiffness (" $2 \mathrm{D}-\mathrm{K}=$ Calculated" in Fig 16) given by $K=E_{\text {eff }} / h_{\text {eff }}\left(=10500 \mathrm{~N} / \mathrm{mm}^{3}\right)$ approaches accurately the analytical solution and even better if $K=1 \mathrm{e} 5 \mathrm{~N} / \mathrm{mm}^{3}$ or $K=1 \mathrm{e} 6 \mathrm{~N} / \mathrm{mm}^{3}$. 


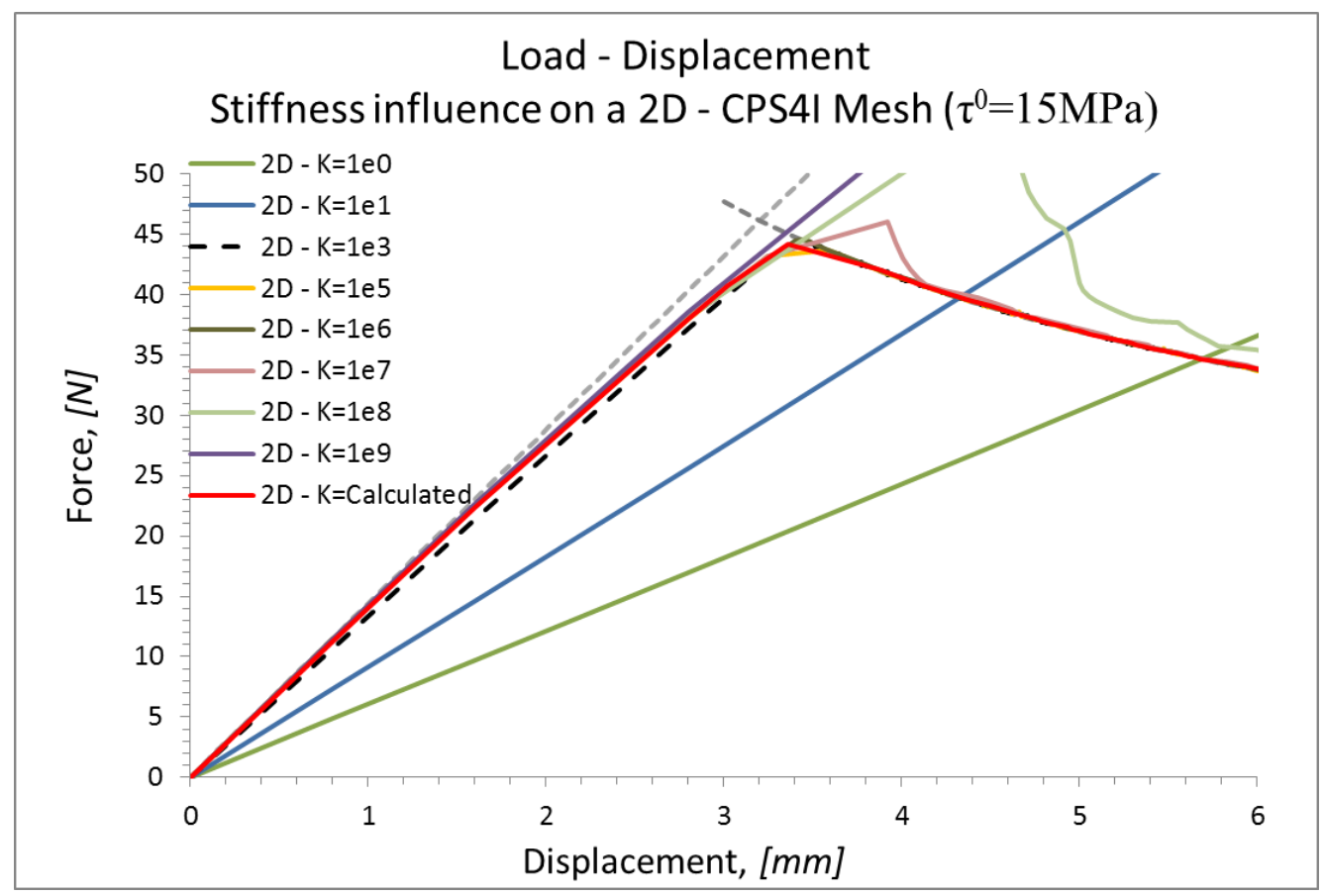

Fig 16 Influence of the stiffness parameter on the simulated load-displacement curves while keeping all other parameters constant

\subsection{Numerical study of a GF/Epoxy DCB test sample}

\subsubsection{Geometry}

The dimensions of the GF/Epoxy DCB test sample CET 5 can be found in 3.1. A pre-crack $a_{0}$ of $35.45 \mathrm{~mm}$ was taken into account with the height $h$ of each substrate equal to 1.5 and a strength $\tau^{0}=60 \mathrm{MPa}$. The strength corresponds to the value of the tensile strength of the Epicote RIMR 135 epoxy resin [49]. A 2D model was built and the finite element mesh of the substrates was constructed using 7800 linear quadrilateral (CPS4I) elements with 5 elements through the thickness per substrate. For the crack initiation and propagation simulation, a layer of cohesive elements was inserted in between the substrates existing of 425 linear quadrilateral cohesive elements $(1=0.2 \mathrm{~mm})$. In order to verify the effect of the asymmetric thicknesses of the substrates of the DCB test specimen, two models with different heights of the individual substrates were simulated. The first model has a height $h_{1}=1.4 \mathrm{~mm}$ of the half of the thickness of the DCB specimen with $\mathrm{h}_{2}=1.6 \mathrm{~mm}$ being the height of the opposite substrate. The second model was built with $\mathrm{h}_{1}=1.45 \mathrm{~mm}$ and $\mathrm{h}_{2}=1.55 \mathrm{~mm}$. Using the material properties defined in combination with a stiffness $K=1 \mathrm{e} 5 \mathrm{~N} / \mathrm{mm}^{3}$ and a viscous regularization factor of 1e-7, one obtains the results as given in section 4.2.2.

\subsubsection{Results}

Model A and model B in Fig 17 show the numerically obtained load-displacement curves corresponding to the critical strain energy release rate values of $G_{I c, \text { ini }}=0.961 \mathrm{~J} / \mathrm{m}^{2}$ and $G_{I c}$, prop $=1.125 \mathrm{~J} / \mathrm{m}^{2}$ determined experimentally as mean values in [27]. The curves correlate with the analytically defined curves, but are diverging from the experimental results. Therefore the influence on the differences in thickness of the substrates (half of the DCB specimens) was analysed and result in the curves shown in model C, D and E in Fig 17. One notices that a small difference in thickness, $0.05 \mathrm{~mm}$, has a big impact on the obtained load-displacement curves leading to more accurate approximation of the experimental results. Model E correlates well with the experiments with $\mathrm{G}_{\mathrm{I} \text {, prop }}=1.125 \mathrm{~N} / \mathrm{mm}$. 


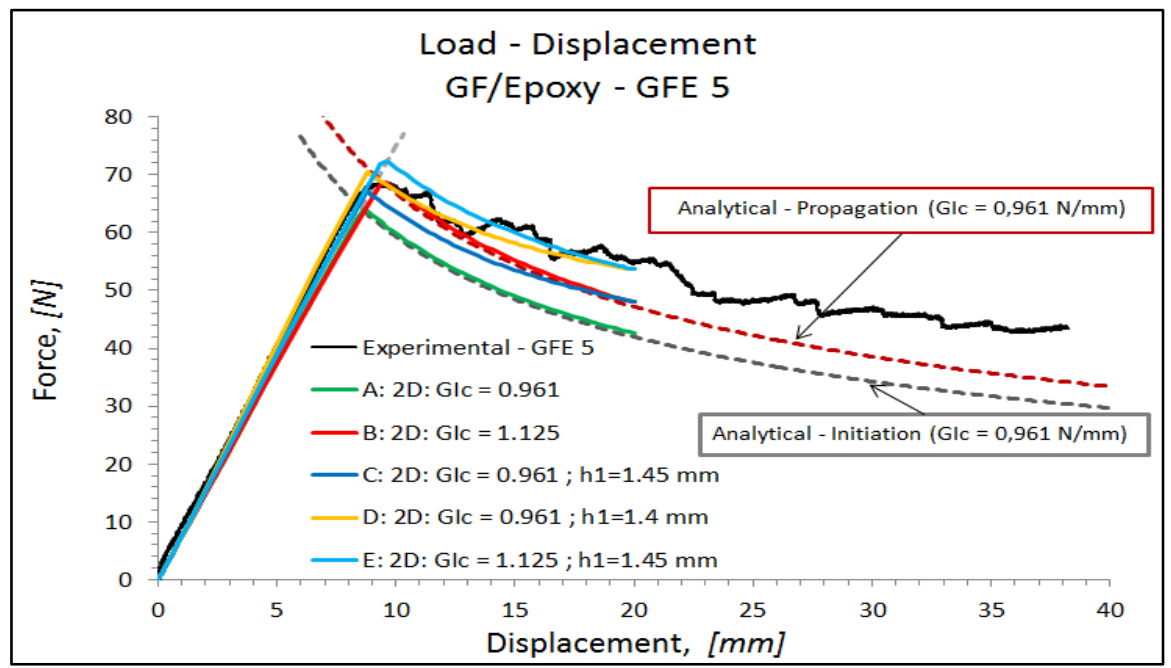

Fig 17 Numerical load-displacement results obtained for a DCB simulation of the GF/Epoxy - GFE 5

\subsection{Numerical study of a CETEX DCB test sample}

\subsubsection{Geometry and properties}

The dimensions of the double cantilever beam test specimen CET 3 of the CETEX material used for the creation of the numerical model can be found in Table 5. A pre-crack $a_{0}$ of 55.1 $\mathrm{mm}$ was taken into account with the height $h$ of each substrate equal to $2.4 \mathrm{~mm}$ with a noncracked length $\mathrm{L}_{1}=66.92 \mathrm{~mm}$ (see Fig 6). A 2D model was built and the finite element mesh of the substrates was constructed using 24410 linear quadrilateral (CPS4I) elements with 5 elements through the thickness per substrate. For the crack initiation and propagation simulation, a layer of cohesive elements was inserted in between the substrates existing of 1338 linear quadrilateral cohesive elements. A very fine mesh $(0.05 \mathrm{~mm})$ was needed in order to be able to obtain converged results with a crack initiation strength $\tau^{0}=90 \mathrm{MPa}$. The reason this value of strength is used, is that the tensile strength for PPS is around $90 \mathrm{MPa}$ [50]. A stabillity factor of $1 \mathrm{E}-7$ with a stiffness $=100000 \mathrm{~N} / \mathrm{mm}^{3}$ were used.

\subsubsection{Results}

Fig 18 shows that the numerically calculated load-displacement curves correlate very well with the analytically predicted curves and with the experiments for the CET 3 test specimen. Both simulation results with $\mathrm{G}_{\mathrm{Ic}}$, Min and $\mathrm{G}_{\mathrm{Ic} \text {, Max }}$ define a band in which the experimental results can fit.

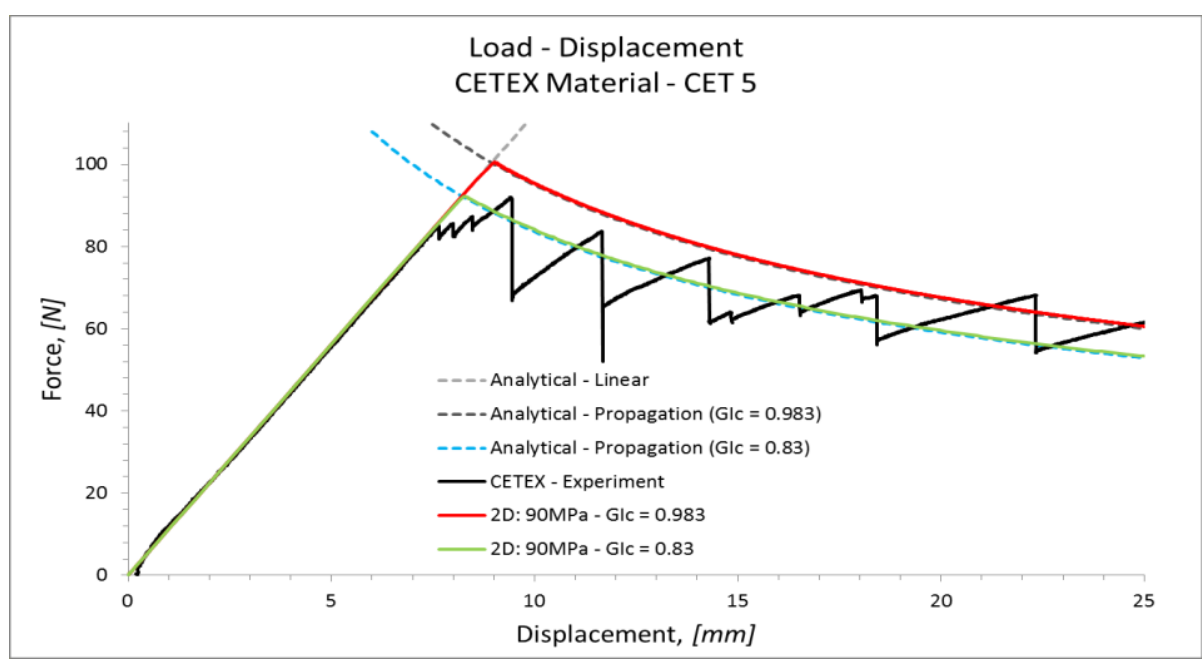

Fig 18 Numerical load-displacement results obtained for a DCB simulation of the CETEX material 


\section{Numerical simulation of a mode II ENF test}

Like mentioned for the DCB mode I simulations, a lot of research has been accomplished on the simulation of the mode II end notched flexure (ENF) test. Again in many cases not all the different parameters are given in order to reproduce the same simulations using the same models and material parameters. Together with the parameters highlighted in the previous section 4, the influence of some extra parameters has been investigated like:

1. position of the supporting and loading rod on the sample

2. influence of the thickness of the substrates and the strength

3. influence of the friction (internal and external)

The geometrical dimensions of the ENF test sample CET 7 and CET 8, together with the material properties for the CETEX test samples can be found in section 3. The geometrical properties of the numerical ENF model can be found in Fig 19.

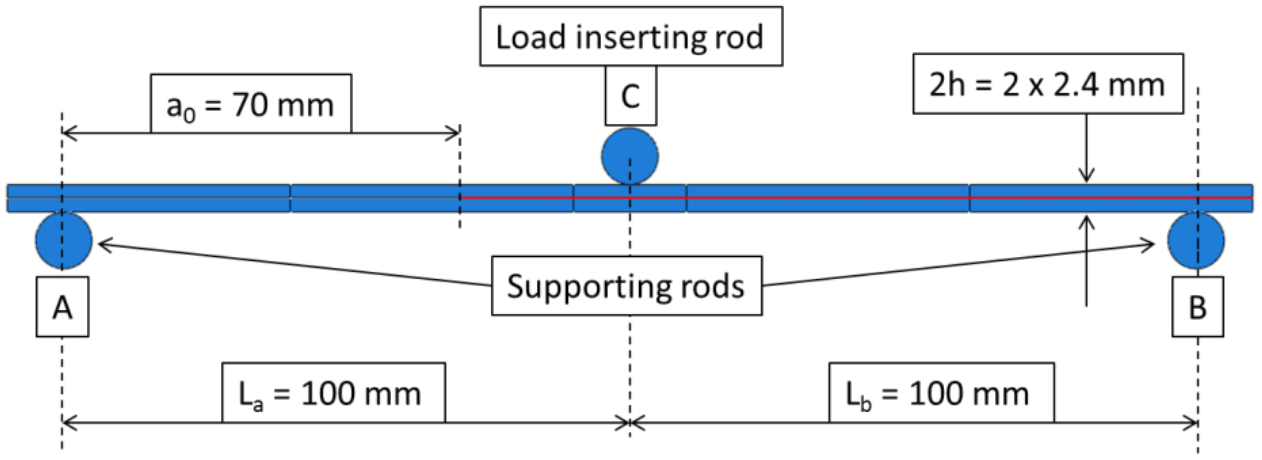

Fig 19 Geometrical properties of the ENF model of the CETEX CET 7 and CET 8 test sample

In between the different rods (Steel) and the contact surfaces of the substrates (PPS) of the ENF sample, friction was taken into account. Friction was also introduced in between the substrates of the sample itself in the region of the pre-crack. While the supporting rods are fixed, a displacement is imposed to the load inserting rod which will introduce the load into the numerical ENF test sample as it is done in real experimental test setups. In order to be sure to capture the different numerical aspects of the ENF simulation, two models, a 2D and a 3D model have been constructed. After a mesh convergence for the two models and stabilization convergence, further study was made using a 2D model existing of 22000 linear quadrilateral elements (CPS4I) and 1400 linear quadrilateral cohesive elements $(1=0.1 \mathrm{~mm})$ and 2366 elements for the rods. The 3D model was built using 18400 linear quadrilateral shell elements (S4) and 400 linear quadrilateral cohesive elements with variation in lengths $\left(1_{\min }=\right.$ $0.2 \mathrm{~mm}$ and $1_{\max }=1 \mathrm{~mm}$ ) reducing the calculation time, plus the elements needed to represent the rods. The mode II average critical energy release rates $\mathrm{G}_{\text {IIc }}\left(=3400 \mathrm{~J} / \mathrm{m}^{2}\right)$ [27] is used in the simulations. The results were exported at each time increment. A stabilization convergence study concerning the viscous regularization factor for the $3 \mathrm{D}$ numerical models of the ENF test was performed. The friction coefficient between the PPS substrates and the steel rods equals 0.25 [51] and is simulated with a master-slave contact interaction with a finer mesh of the slave part compared to the master part. The influence of this friction coefficient has been studied by variation of the friction coefficient which will be shown in later section 5.1.3. The shear strength of PPS [50] is around $60 \mathrm{MPa}$, therefore this value will be used together with a value of $30 \mathrm{MPa}$ and $90 \mathrm{MPa}$ in order to show the influence of the strength parameter. A stiffness of $1 \mathrm{e} 6$ and a viscous regularization factor between $1 \mathrm{e} 5-1 \mathrm{e} 8$ was used in the simulations. The $3 \mathrm{D}$ model with a strength $\tau^{0}=90 \mathrm{MPa}$ will be considered as a reference in following studies since this value corresponds the closest to the analytical solution. 


\subsection{Parametric study}

In order to capture the impact of the variations of different parameters, multiple studies have been effectuated and compared to a reference.

\subsubsection{Position of the rods}

\section{$\underline{\text { Translations }}$}

The reference model has a half span $\mathrm{L}_{\mathrm{a}}=100 \mathrm{~mm}$ and $\mathrm{L}_{\mathrm{b}}=100 \mathrm{~mm}$ (Fig 19) and this has been changed in order to check the sensitivity of the results to such variations. A study was performed with an asymmetric support with a half span on one side $L_{a}=98 \mathrm{~mm}$ while keeping the original $\mathrm{L}_{b}=100 \mathrm{~mm}$ on the other side (Fig 19) and can be find as model TRAN $\mathrm{C}$ in Fig 20. A similar simulation was made but with opposite asymmetry with $\mathrm{L}_{\mathrm{a}}=100 \mathrm{~mm}$ and $\mathrm{L}_{\mathrm{b}}=98 \mathrm{~mm}$ (Fig 19), see model TRAN C. The results as given in Fig 20 show that some variations may occur when the positions of the rods are changed. For example when comparing model TRAN A, TRAN B and TRAN C, a small shift of the load-displacement curve can be noticed which represents a stiffening of the response due to the decrease of the leverage. One can also see that if the central rod, inducing the load on the test sample, is slightly shifted (TRAN D and TRAN E), one can obtain a difference in maximum force between the ideal positioning $\left(\mathrm{L}_{\mathrm{a}}=\mathrm{L}_{\mathrm{b}}=100 \mathrm{~mm}\right)$ and the shifted ones of approximately $3 \%$ for this material and configuration.

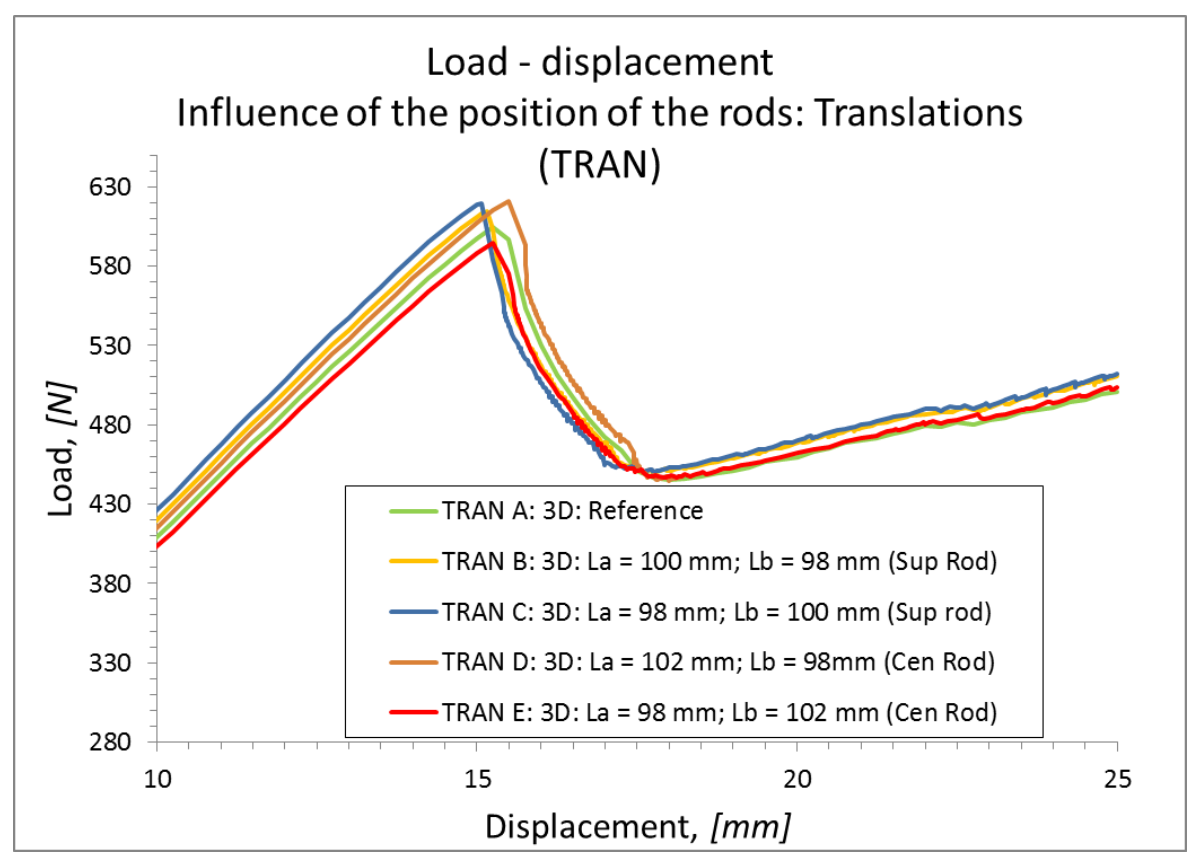

Fig 20 Influence of the position of the rods - Translations - on the numerical load-displacement curves of the ENF simulation

\section{$\underline{\text { Rotations }}$}

The influence of the rotations of the supporting rods and the central rod as depicted in Fig 21, was investigated. Model ROT B and ROT C show the load-displacement results for the simulations where both supporting rods are rotated like given in point $\mathrm{A}$ and point $\mathrm{B}$ of Fig 21 by 1 degree respectively 2 degrees. The last model presents the results of a model where only the central, load inserting rod, has been rotated by 2 degrees. 


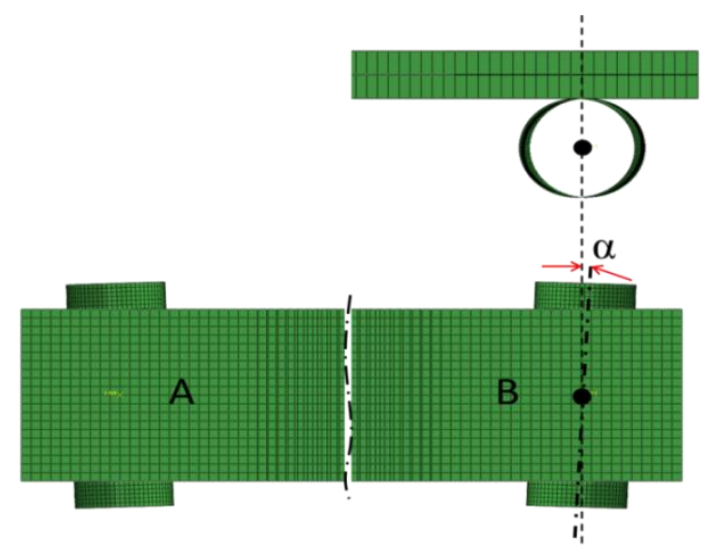

Fig 21 Rotation of a rod by $\alpha$ degrees

A small rotation of the two supporting or the central rods does not have any significant effect on the resulting load-displacement curves. All the load-displacement curves of the different models coincide with the reference model with the ideally positioned rods.

\subsubsection{Influence of the thickness of the substrates and the strength}

This study aims to check the influence of the thickness of half of the total thickness of the test sample h (Fig 19). The models used for this study are based on the reference $2 \mathrm{D}$ model. The thicknesses of the substrates of this model have been changed from $2 \times(h=2.4 \mathrm{~mm})$ into $h_{\text {top }}$ $=2.35 \mathrm{~mm}$ and $\mathrm{h}_{\text {bot }}=2.45 \mathrm{~mm}$. $\mathrm{h}_{\text {top }}$ represents the thickness of the substrate at the top in contact with the load inserting rod. Additionally the thickness $h_{\text {top }}$ has been reduced to $h_{\text {top }}=$ $2.3 \mathrm{~mm}$ with $\mathrm{h}_{\text {bot }}=2.5 \mathrm{~mm}$. The influence of the thickness of the substrates of the ENF simulated test sample cannot be noticed in contrary to the similar graphs shown for the DCB simulation.

\subsubsection{Influence of the friction}

Since it is not always mentioned in the reports or papers dealing with experimental ENF tests what the friction coefficient between the rods and the contact surface of the substrates of the test sample is, a numerical study was effectuated in order to find out what the impact could be on the resulting load-displacement curves. Therefore it was chosen to perform the quasi-static simulations using the 3D reference model with different friction coefficients at multiple failure strengths $\tau_{0}(30,60$ and $90 \mathrm{MPa})$. Both the impact of the friction between the substrates of the ENF model (INT) as well as the friction at the contact surface between the rods and the substrates (EXT) has been studied. At last a combination of the effect due to the friction at the contact surface and the strength is shown. The internal friction is experimentally very hard to measure and this is future work to be done. On the other hand the friction between the rods and the test samples can be measured easily.

Internal friction between the substrates of the model

The influence due to the friction between the surfaces of the substrates of the numerical test sample is very low. Only a small shift of the curve can be noticed comparing a friction coefficient of 0.01 to a friction coefficient of 0.4 leading to a maximum force difference of less than $1 \%$.

External friction between the substrates and the rods

Here it is investigated what the effect of the friction between the rods and the substrates can be. Since in reality these rods are supposed to produce very little friction, the values for the friction coefficient were varied between 0.01 for model EXT A, 0.33 for model EXT B and 
0.4 for model EXT C. The strength $\tau^{0}$ at failure initiation used for this investigation equals 30 $\mathrm{MPa}$. All the results of the output were written out at each time increment of the simulation.

Although the shape of the load-displacement curves of the results (Fig 22) remains similar, a shift in loads can be observed. A difference between the minimum load for model EXT A (corresponding to almost no friction) and model EXT $\mathrm{C}$ reaches up to $8 \%$ which is not negligible.

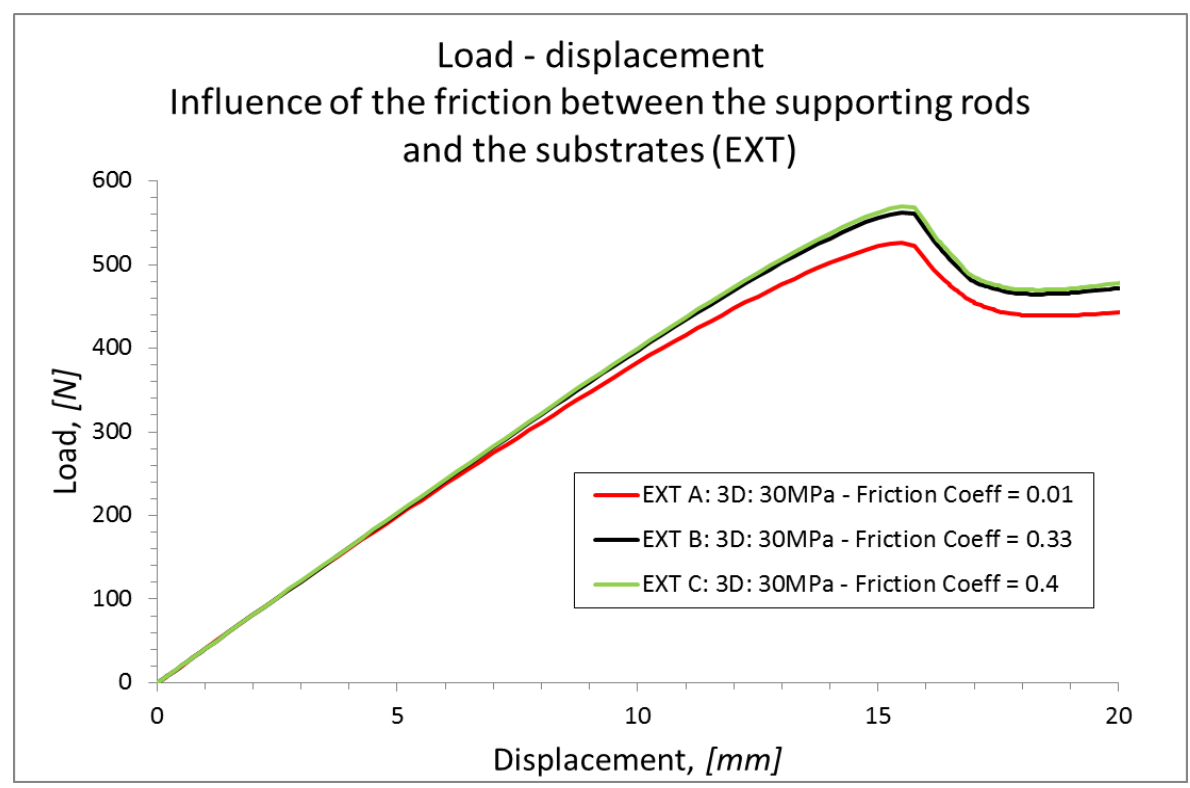

Fig 22 Influence of the friction between the substrates and the rods (EXT) on the numerical loaddisplacement curves of the ENF simulation

\section{Combination of friction and strength}

When combining the influences due to the external friction and the strength in one graph (Fig 23 ) it is obvious that these effects impact a lot the simulated results. A difference in maximum force between the minimum value obtained with model COM $\mathrm{C}$ and the maximum value obtained with model COM D represents an increase of approximately $20 \%$.

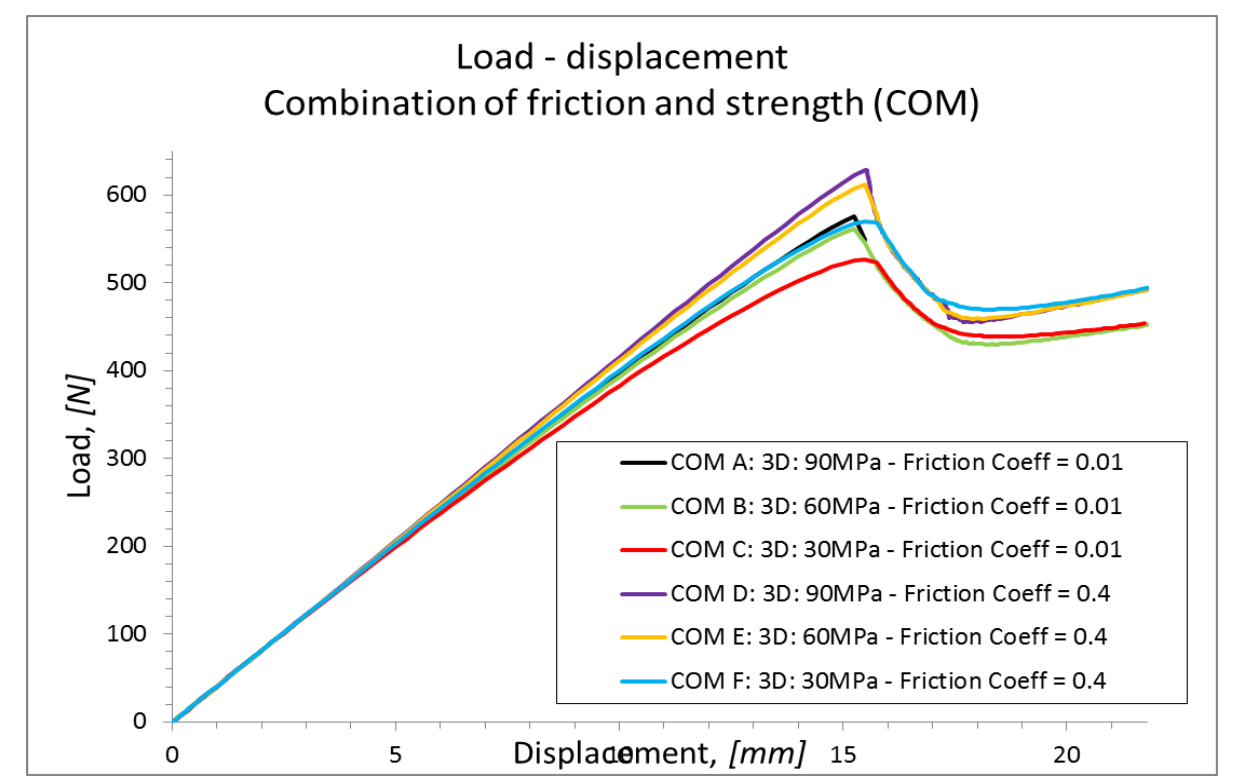

Fig 23 Load-displacement curves of ENF numerical simulations with combinations of influences due to friction and strength 
If the lessons from these studies are applied to the simulation of an ENF test one obtains a good correlation between the experimental results (CET 7 and CET 8) as defined in section 3 and the numerical load-displacement curves (Fig 24). The analytical curves have been constructed with the maximum and minimum critical strain energy release rates $\mathrm{G}_{\text {IIc }}$ defined experimentally [27]. The difference between the experimental and analytical results is due to the friction between the rods and the substrates and the failure strength $\tau^{0}$ in the tractionseparation law. This proves the added value of such numerical simulations.

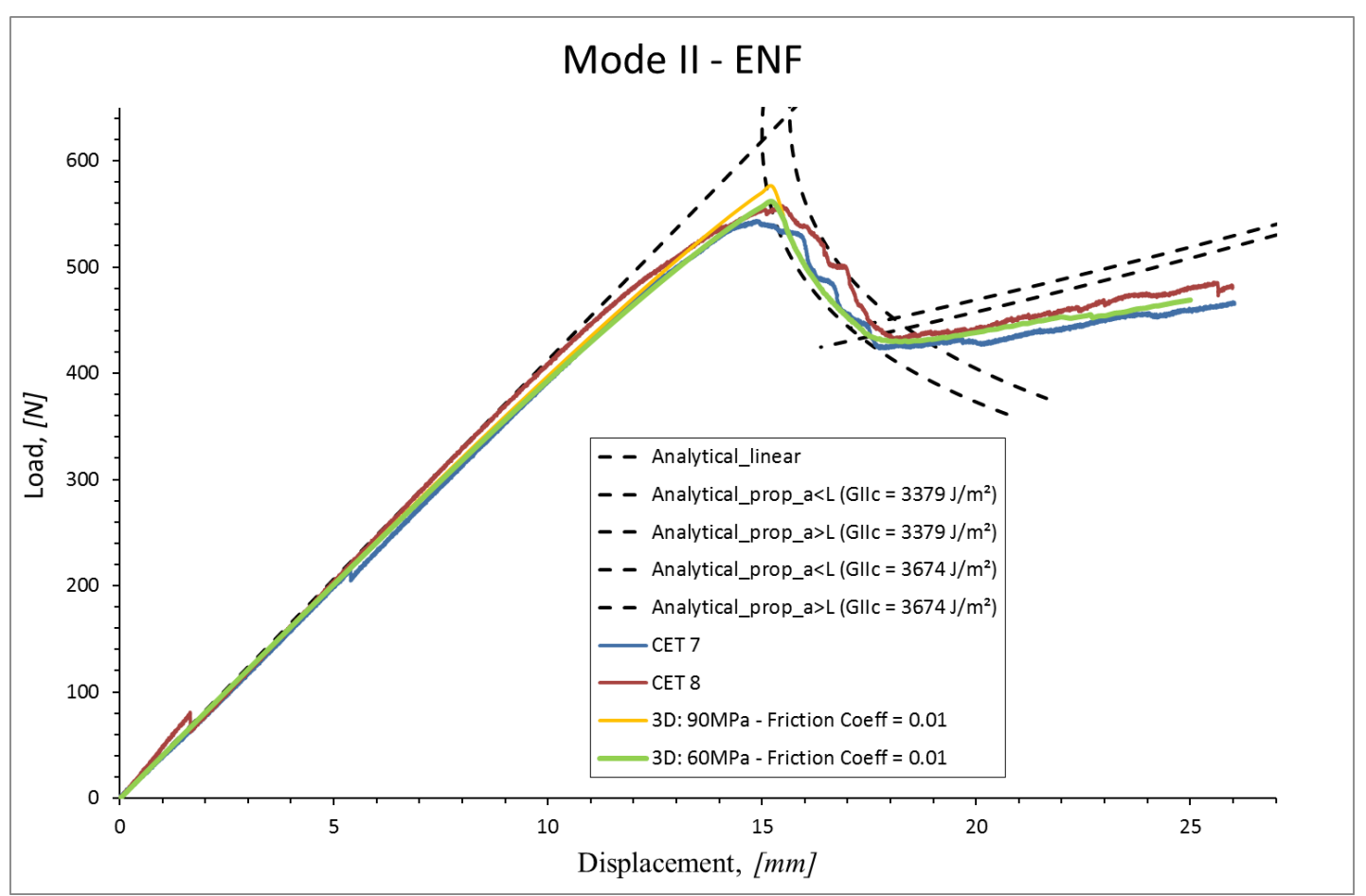

Fig 24 Load-displacement curves of the ENF numerical and experimental test results

\section{Conclusions}

After a complete analysis on the parameters influencing the numerical results, a good correlation was obtained between the simulated, the experimental and the analytical loaddisplacement curves when the different factors combined are taken into account. It was numerically proven that for the mode I (DCB) analysis a small change in thickness of one of the two substrates composing the composite can lead to other results than expected by the analytical solution. A same conclusion can be drawn concerning the friction for the mode II (ENF) and the supporting rods leading to different results between the crack propagation parts of the load-displacement curves.

A general conclusion when dealing with numerical and experimental tests of mode I and mode II or delaminations in general is that when one wants to achieve a correlation between the experimental and numerical curves, it would be better to give a range in which the numerically obtained curves would be using different parameters, than giving a result correlating with one curve because of the impact of the different numerical parameters. It is advised that for all numerical simulations, all details needed for the numerical simulations would be given in the manuscripts.

Finally a summary of the parameters with their impact on the results can be found in Table 10. Since all parameters can influence one another, no explicit values can be advised, but the table will help the reader checking the parameters. 


\begin{tabular}{|c|c|c|c|}
\hline Parameter & & Comment & Mode \\
\hline \multirow[t]{3}{*}{ Stabilization method } & & the maximum dissipated energy has to be checked & I and II \\
\hline & viscous regularization & $\begin{array}{l}\text { the lower the stability factor the higher the } \\
\text { computational time }\end{array}$ & I and II \\
\hline & automatic stabilization & $\begin{array}{l}\text { the automatic stabilization has a big impact on the } \\
\text { computational time but can be used to define the } \\
\text { value for viscous regularization (see manuscript) }\end{array}$ & I and II \\
\hline \multirow[t]{3}{*}{ Output frequency of data } & & $\begin{array}{l}\text { Sufficient amount of data points have to be } \\
\text { considered in order to capture the maxima }\end{array}$ & I and II \\
\hline & & & I and II \\
\hline & & & I and II \\
\hline \multirow[t]{2}{*}{ Models (2D, 3D, shell, solid) } & & $\begin{array}{l}\text { Simular results can be achieved but of course there is } \\
\text { an impact on computationakl times }\end{array}$ & I and II \\
\hline & & & I and II \\
\hline \multirow[t]{2}{*}{ Mesh } & & $\begin{array}{l}\text { very fine meshes in the crack tip area (cohesive zone) } \\
\text { are needed in order to capture the maxima and the } \\
\text { mesh is dependent on all other parameters }\end{array}$ & I and II \\
\hline & & & I and II \\
\hline Strength & & $\begin{array}{l}\text { an impact on the maxima can be observed as well as } \\
\text { on the linear part of the load-displacement graph }\end{array}$ & I and II \\
\hline Stiffness & & $\begin{array}{l}\text { correct results will be obtained for stiffnesses } \\
\text { beneath a maximum and above a minimum threshold } \\
\text { however the results will converge for stiffnesses out } \\
\text { of this zone }\end{array}$ & I and II \\
\hline thickness of the substrates & & $\begin{array}{l}\text { for mode I simulations a big impact can be noticed; } \\
\text { less influence is observed for mode II simulations }\end{array}$ & I and II \\
\hline \multirow[t]{2}{*}{ position of the rods } & rotation & $\begin{array}{l}\text { for small angles, no significant influence on the } \\
\text { obtained numerical results can be noticed }\end{array}$ & II \\
\hline & translation & $\begin{array}{l}\text { the positioning of the central / supporting rods will } \\
\text { have an impact on the final maxima and the load- } \\
\text { displacement curves of the mode II results }\end{array}$ & II \\
\hline \multirow[t]{2}{*}{ Friction } & internal friction & a small impact on the results was observed & II \\
\hline & external friction & $\begin{array}{l}\text { significant diffrences of the load-displacement curves } \\
\text { are computed using different friction coefficients }\end{array}$ & II \\
\hline
\end{tabular}

Table 10: Summarizing table of the parameters and their impact on the numerical results 


\section{References}

[1] E F Rybicki and M F Kanninen, "A finite element calculation of stress intensity factors by a modified crack closure integral," Engineering Fracture Mechanics, vol. 9, no. 4, pp. 931-938, 1977.

[2] Ronald Krueger, "The Virtual Crack Closure Technique: History, Approach and Applications," NASA/CR-2002-211628, ICASE Report N²002-10, 2002.

[3] J R Rice, "A Path Independent Integral and the Approximate Analysis of Strain Concentration by Notches and Cracks ," Journam of Applied Mechanics, vol. 35, pp. 379-386, 1968.

[4] C E Inglis, "Stresses in a plate due to the presence of cracks and sharp corners," Transactions of the Royal Institute of Naval Architects, vol. 60, pp. 219-241, 1913.

[5] H M Westergaard, "Bearing pressures and cracks," Journal of Applied Mechanics, vol. 49-53, 1939.

[6] A A Griffith, "The Phenomena of Rupture and Flow in Solids," Philiosphical Transactions of the Royal Society of London. Series A, Containing Papers of a Mathematical or Physical Character, vol. 221, pp. 163-198, 1921.

[7] G I Barenblatt, "The mathematical theory of equilibrium cracks in brittle fracture," in Advances in applied mechanics, Volume 7, Elsevier, Ed., 1962, ch. 2.

[8] D S Dugdale, "Yielding of steel sheets containing slits," Journal of the Mechanics and Physics of Solids, vol. 8, no. 2, pp. 100-104, 1960.

[9] A Turon, P P Camanho, J Costa, and C G Dávila, "An Interface Damage Model for the Simulation of Delamination Under Variable-Mode Ratio in Composite Materials," NASA/TM-2004-213277, p. 32, 2004.

[10] A Turon, P P Camanho, J Costa, and C G Dávila, "A damage model for the simulation of delamination in advanced composites under variable-mode loading," Mechanics of Materials, vol. 38, pp. 1072-1089, 2006.

[11] C Shet and N Chandra, "Analysis of energy balance when using cohesive zone models to simulate fracture processes," Transactions of the ASME, vol. 124, pp. 440-450, 2002.

[12] Alan Needleman, "A Continuum Model for Void Nucleation by Inclusion Debonding," Journal of Applied Mechanics-transactions of The Asme, vol. 54, no. 3, pp. 525-531, 1987.

[13] Viggo Tvergaard and John W Hutchinson, "The relation between crack growth resistance and fracture process paramaters in elastic-plastic solids," J. Mech. Phys. Solids, vol. 40, no. 6, pp. 1377-1397, 1992.

[14] X-P Xu and A Needleman, "Void nucleation by inclusion debonding in a crystal matrix," Modelling Simul. Mater. Sci. Eng., vol. 1, pp. 111-132, 1993.

[15] X-P Xu and A Needleman, "Numerical simulations of fast crack growth in brittle solids," J. Mech. Phys. Solids, vol. 42, no. 9, pp. 1397-1434, 1994.

[16] G T Camacho and M Ortiz, "Computational modelling of impact damage in brittle materials," Int. J. Solid Structures, vol. 33, no. 20-22, pp. 2899-2938, 1996.

[17] Philippe H Geubelle and Jeffrey S Baylor, "Impact-induced delamination of composites: a 2D simulation," Composites Part B, vol. 29B, pp. 589-602, 1998.

[18] P P Camanho and C G Dávila, "Mixed-Mode Decohesion Finite Elements for the Simulation of Delamination in Composite Materials," NASA/TM, vol. 211737, pp. 1-42, 2002.

[19] G Alfano and M A Crisfield, "Finite element interface models for the delamination 
analysis of laminated composites: mechanical and computational issues," Int. J. Numer. Meth. Engng, vol. 50, pp. 1701-1736, 2001.

[20] P Davies, B R K Blackman, and A J Brunner, "Standard Test Methods for Delamination Resistance of Composite Materials: Current Status," Applied Composite Materials, vol. 5, pp. 345-364, 1998.

[21] T Kevin O'Brien, "Interlaminar fracture toughness: the long and winding road to standardization," Composites Part B: Engineering, vol. 29, no. 1, pp. 57-62, 1998.

[22] A J Brunner, B R K Blackman, and P Davies, "A status report on delamination resistance testing of polymer-matrix composites," Engineering Fracture Mechanics, vol. 75, pp. 2779-2794, 2008.

[23] R Martin and B D Davidson, "Mode II fracture toughness evaluation using a four point bend end notch flexure test.," Proceedings of the 4th international conference on deformation and fracture of composites, pp. 243-252, 1997.

[24] B D Davidson and X K Sun, "Effects of Friction, Geometry, and Fixture Compliance on the Perceived Toughness from Three-and Four-Point Bend End-Notched Flexure Tests," Journal of reinforced plastics and composites, vol. 24, no. 15, pp. 1611-1628, 2005.

[25] International ASTM, "Standard test method for Mode I interlaminar fracture toughness of unidirectional fiber-reinforced polymer matrix composites," ASTM Designation: D5528-01, 2007.

[26] Stefan Jacques, Ives De Baere, and Wim Van Paepegem, "Application of periodic boundary conditions on multiple part finite element meshes for the meso-scale homogenization of textile fabric composites," Composites Science and Technology, vol. 92, pp. 41-54, 2014.

[27] Ives De Baere, Stefan Jacques, Wim Van Paepegem, and Joris Degrieck, "Study of the Mode I and Mode II interlaminar behaviour of a carbon fabric reinforced thermoplastic," Polymer Testing, vol. 31, no. 2, pp. 322-332, April 2012.

[28] J P Berry, "Determination of Fracture Energies by the Cleavage Technique," Journal of Applied Physics, vol. 34, no. 1, pp. 62-68, 1963.

[29] B D Davidson, M A Soffa, and M Kumar, "Temperature and Moisture Effects in a Particulate Interlayered Composite: Mode I Data Reduction and Toughness," JOURNAL OF REINFORCED PLASTICS AND COMPOSITES, vol. 28, no. 17, pp. 2049-2068, 2009.

[30] F X de Charentenay, J M Harry, Y J Prel, and M L Benzeggagh, "Characterizing the Effect of Delamination Defect by Mode I DelaminationTest," in Effects of defects in Composite Materials.: American Society for Testing and Materials, 1984, pp. 84-103.

[31] J G Williams, "The Fracture Mechanics of Delamination Tests," Journal of Strain Analysis, vol. 24, no. 4, pp. 207-214, 1989.

[32] K Kageyama and M Hojo, "Proposed Methods for Interlaminar Fracture Toughness Tests of Composite Laminates," in 5th U.S./Japan Conference on Composite Materials, Tokyo, 1990, pp. 227-234.

[33] S Hashemi, A J Kinloch, and J G Williams, "Corrections Needed in Double Cantilever Beam Tests for Assessing the Interlaminar Failure of Fiber Composites," Journal of Materials Science Letters, vol. 8, pp. 125-129, 1989.

[34] M N Charalambides and J G Williams, "MODE-I DELAMINATION OF ANGLE-PLY EPOXY-GLASS-FIBER LAMINATES EXHIBITING PERMANENT DEFORMATION DURING FRACTURE," Composites Science and Technology, vol. 50, pp. 187-196, 1994. 
[35] J A Bergley and J D Landes, "The J integral as a Fracture Criterion," American Society for Testing and Materials, pp. 1-20, 1972.

[36] J G Williams, "End Corrections for Orthotropic DCB Specimens," Composites Science and Technology, vol. 35, pp. 367-376, 1989.

[37] International ASTM, "New Test Method for Determination of the Mode II Interlaminar Fracture Toughness of Unidirectional Fiber-Reinforced Polymer Matrix Composites Using the End-Notched Flexure (ENF) Test ," ASTM Designation: WK22949, 2009.

[38] J D Barrett and R O Foschi, "Mode II stress-intensity factors for cracked wood beams," Engineering fracture mechanics, vol. 9, pp. 371-378, 1977.

[39] P S Vanderkley, Mode I - Mode II delamination fracture toughness of a unidirectional graphitelepoxy composite, Master thesis. Texas: Texas A\&M University, 1981.

[40] L A Carlsson and J W Gillespie, "Mode II interlaminar fracture of composites," Application of fracture mechanics to composite materials, 1989.

[41] D Davies et al., "Comparison of test configurations for the determination of GIIc: results from an international round robin," Plastics, Rubber and Composites, vol. 28, no. 9, pp. 432-437, September 1999.

[42] P P Camanho, A Turon, C Sarrado, G Guillamet, and D Trias, "Simulation of delamination in polymer composites: best practices at different levels of analysis.," in Technical interchange meeting ESA/ESTEC, Noordwijk, 2011.

[43] A Turon, P P Camanho, J Costa, and J Renart, "Accurate simulation of delamination growth under mixed-mode loading using cohesive elements: Definition of interlaminar strengths and elastic stiffness," Composite structures, vol. 92, pp. 1857-1864, 2010.

[44] M Bruyneel, J-P Delsemme, Ph Jetteur, and F Germain, "Modeling Inter-Laminar Failure in Composite Structures: Illustration on an Industrial Case Study," Appl Compos Mater, vol. 16, pp. 149-162, 2009.

[45] G A O Davies and I Guiamatsia, "The Problem of the Cohesive Zone in Numerically Simulating Delamination/Debonding Failure Modes," Applied Composite Materials, vol. 19, pp. 831-838, 2012.

[46] Albert Turon, Carlos G Dávila, Pedro P Camanho, and Jodep Costa, "An Engineering Solution for using Coarse Meshes in the Simulation of Delamination With Cohesive Zone Models," NASA/TM-2005-213547, p. 26, 2005.

[47] Qingda Yang and Brian Cox, "Cohesive models for damage evolution in laminated composites," International Journal of Fracture, vol. 133, pp. 107-137, 2005.

[48] Michael L Falk, Alan Needleman, and James R Rice, "A critical evaluation of dynamic fracture simulations using cohesive surfaces," in Jounal de Physique IV, 2001, pp. 5-43 to $5-50$.

[49] Momentive, "Technical data sheet of the Epikote Resin MGS RIMR 135 - HCD-8246," 2006.

[50] BearingWorks. Bearing Works [Online]. http://www.bearingworks.com/content_files/pdf/retainers/PPS\%20datasheet.pdf

[51] J Quintelier et al., "Wear behavior of carbon fiber reinforced Poly Phenylene Sulfide," Polymer Composites, vol. 27, no. 1, pp. 92-98, 2006. 